\title{
The future of buyer-seller interactions: a conceptual framework and research agenda
}

\author{
Michael Ahearne ${ }^{1} \cdot$ Yashar Atefi $^{2} \cdot$ Son K. Lam ${ }^{3} \cdot$ Mohsen Pourmasoudi $^{4}$
}

Received: 17 November 2020 / Accepted: 19 July 2021 / Published online: 29 September 2021

(c) Academy of Marketing Science 2021

\begin{abstract}
The revolution in information availability and the advances in novel interaction technologies have ushered in two major shifts that call into question the traditional assumptions of buyer-seller interactions. First, buyer-seller information asymmetry has greatly decreased in many interactions. Second, face-to-face communication is no longer the main format of buyer-seller interactions. In this article, the authors review empirical research on how these shifts have changed buyer-seller negotiations, an important type of buyer-seller interactions. Several insights arise from this review. First, the shifts have caused fundamental changes in buyers' and sellers' roles, power, and aspirations and information processing. Second, the shifts and these fundamental changes together cause major changes in buyer-seller interactional processes and outcomes, including (1) change in buyers' attitude and behavior, (2) change in sellers' effectiveness in interacting with buyers, and (3) change in buyer-seller interactional processes. Based on these insights, the authors develop a research agenda to guide the reexamination of existing theories and the development of new theories of buyer-seller interactions.
\end{abstract}

Keywords Buyer-seller $\cdot$ Interactions $\cdot$ Social media $\cdot$ Digital $\cdot$ Information asymmetry $\cdot$ Negotiation $\cdot$ Sales

Buyer-seller interactions refer to exchanges that occur between buyers and sellers. Early frameworks of buyer-seller interactions underscore communication processes (e.g.,

Mark Houston served as editor for this manuscript.

Michael Ahearne

mahearne@uh.edu

Yashar Atefi

Yashar.Atefi@du.edu

Son K. Lam

sonlam@uga.edu

Mohsen Pourmasoudi

mpourmasoudi@sdsu.edu

1 C. T. Bauer College of Business, University of Houston, 334 Melcher Hall, Houston, TX, USA

2 Daniels College of Business, University of Denver, 2101 S. University Blvd., Ste. 486, Denver, CO 80208, USA

3 Terry Dean's Advisory Council Distinguished Professorship, Terry College of Business, University of Georgia, 630 S. Lumpkin Street, C328 Benson Hall, Athens, GA 30602, USA

4 Fowler College of Business, San Diego State University, 5500 Campanile Drive, San Diego, CA 92182, USA
Sheth, 1975) as well as the roles, power, and aspirations of buyers and sellers (e.g., Frazier, 1983; Solomon et al., 1985). Research on buyer-seller negotiations, a specific form of buyer-seller interactions in which the buyer and the seller discuss the terms of their transaction, has also emphasized similar elements. Despite the long-standing interest in the topic and a large body of literature, research on buyer-seller interactions has generally assumed information asymmetry and face-to-face interactions between buyers and sellers. Two important shifts challenge these widely accepted assumptions: the information revolution and recent technological disruptions.

The information asymmetry assumption-that sellers have private information about their products and services that buyers are not aware of-is no longer relevant in many business-to-consumer (B2C) and business-to-business (B2B) contexts due to buyers' easy access to useful information before their interactions with sellers (e.g., Ahearne et al., 2019b; Atefi et al., 2020; Hartmann et al., 2018; Oh, 2017). The automotive industry represents a good example, as car buying has fundamentally changed with the emergence of dozens of third-party platforms (e.g., TrueCar, Autotrader, Edmunds). These platforms not only reveal important information, such as the average price paid by 


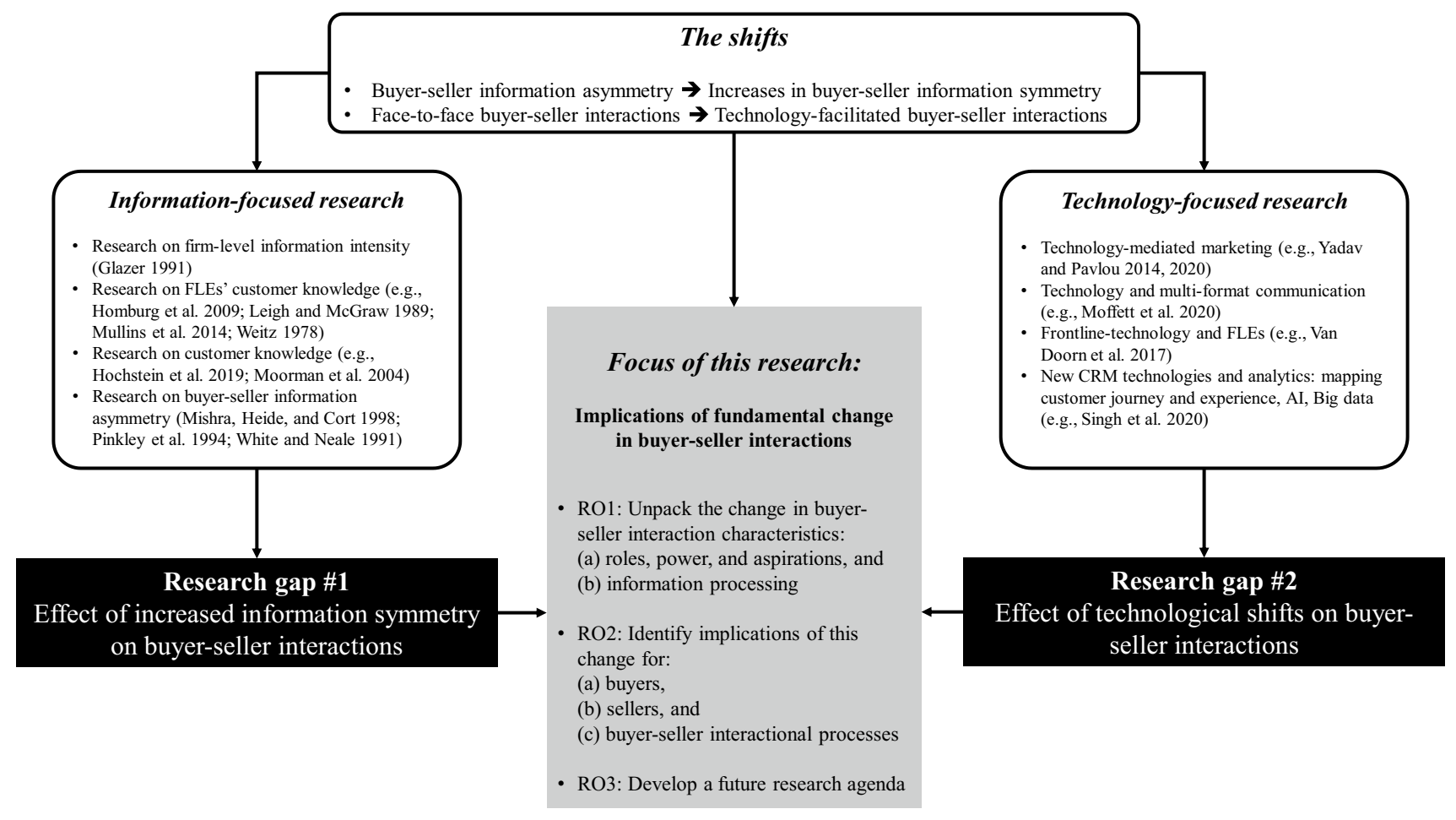

Fig. 1 Literature review. Note: $R O$ research objective

customers for a given model in a given zip code but also expose sellers' bottom line by showing the dealership's factory invoice price. Buyer-seller platforms such as eBay also give buyers the option to see the pricing of similar products as well as seller's reviews before bidding on the desired item (Backus et al., 2020).

Importantly, access to rich data is not limited to consumer markets. According to an Accenture (2014) study, more than $90 \%$ of business buyers extensively use thirdparty websites to collect information before connecting with a seller. On these websites, cost information is coupled with other information such as qualities, product features and configurations, customer reviews, and other information specific to the particular industry. For instance, information on industrial machinery is widely available on websites such as machineseeker.com or machinerytrader.com. B2B enterprise software buyers can use information on websites such as Capterra.com or softwareadvice.com. Websites such as Fixr.com, buyerzone.com, or costowl.com help construction customers search for cost information. Buyers in the transportation industry benefit from informative websites such as boattrader.com and findaircraft.com.

In addition to the informational shift, recent technological advances have diversified buyer-seller interaction media, from traditional face-to-face interactions to technology-enabled and multi-format interfaces (e.g., chat boxes, email, e-negotiations). Moreover, the increasing use of video-conferencing tools such as Zoom, Skype, and Microsoft Teams during the COVID-19 pandemic has made these platforms the main format for buyer-seller interactions around the world. The impact of technologies on marketing is visible across nearly every business sector and multi-format communications have become the norm (Grewal et al., 2020; Moffett et al., 2020).

As we review in Fig. 1, prior research has provided useful insights into the role of information in buyer-seller interactions, including the importance of firm-level information intensity, the impact of frontline employees' (FLEs) customer knowledge, the role of customer knowledge, and the role of information asymmetry. Although research on the role of technologies in buyer-seller interactions is much more recent, this body of literature has shed light on various issues such as technology-mediated marketing, multiformat communications, the interplay of technologies and FLEs, and the usefulness of machine learning in analyzing customer journeys and negotiations (Marinova et al., 2018; Moffett et al., 2020; Singh et al., 2020; Yadav \& Pavlou, 2014). While marketing researchers have begun examining the impact of informational and technological shifts on buyer-seller interactions (e.g., Ahearne et al., 2019b; Atefi et al., 2020; Grewal et al., 2020; Köhler et al., 2011; Moffett et al., 2020; Yadav \& Pavlou, 2014), a systematic review of the implications of these shifts for theory and practice of buyer-seller interactions is still missing. 


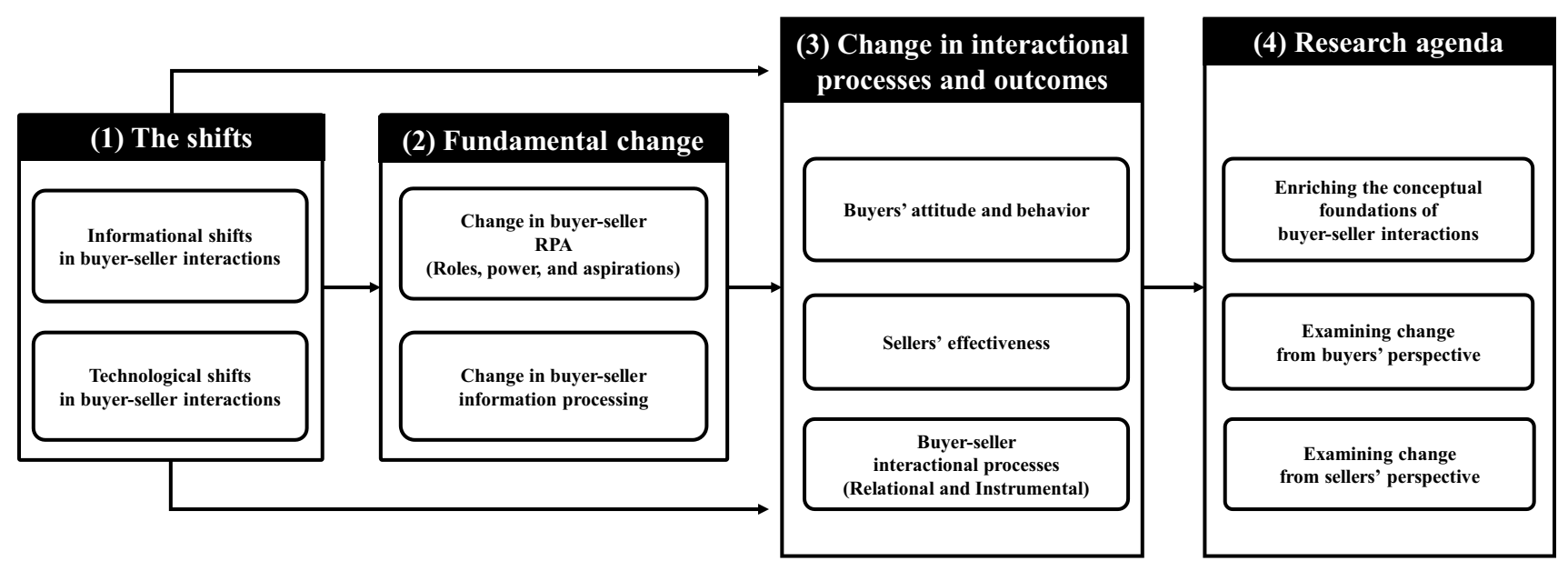

Fig. 2 Review framework

Such an examination is important for at least three reasons. First, having an understanding of the theoretical implications of these shifts would enable researchers to revise existing theories and identify new theories for contemporary buyer-seller interactions (MacInnis, 2011; Palmatier et al., 2018). Second, without a deep understanding of the managerial implications of these shifts, managers will not be able to achieve effectiveness in their interactions with the new class of buyers. Lusch et al., (2006: 272) contend that "in a globally networked and open economy, information symmetry becomes essential because the system will drive out those organizations that are not trustworthy or symmetric in information provision." Third, the insights gleaned from a systematic review and research agenda are relevant to both B2C and B2B interactions.

Our research has three objectives, as summarized in our review framework in Fig. 2. First, we unpack how the informational and technological shifts in buyer-seller interactions fundamentally alter two key traditional assumptions in this domain: informational asymmetry and a face-toface mode of interactions. Second, we draw from research on negotiation in both marketing and adjacent domains to illustrate how the violation of these traditional assumptions leads to fundamental changes in buyers' and sellers' roles, power, and aspirations and information processing (Fig. 2, Box $1 \rightarrow$ Box 2). In addition, the shifts and these fundamental changes together influence buyers' attitude and behavior, sellers' effectiveness, and their interaction processes, including relationship building and problem solving (Fig. 2, Box 1 and Box $2 \rightarrow$ Box 3 ). Third, using insights from these two research questions, we develop an agenda for future research on buyer-seller interactions (Fig. 2, Box 4).

The contributions of our research to the literature on buyer-seller interactions involve envisioning and explicating (MacInnis, 2011). First, we envision a new reality of buyer-seller interactions. We are not the first one to identify the informational and technological shifts (e.g., Ahearne et al., 2019b; Atefi et al., 2020; Hartmann et al., 2018; Oh, 2017), but we are the first to systematically identify the farreaching implications of these shifts for contemporary and future buyer-seller interactions. In doing so, we underscore the need to revise traditional marketing theories that are heavily based on buyer-seller informational asymmetry (to account for increased information symmetry) and technologies as merely a means for interactions (to account for technologies as the cause of changes in how interactions unfold). This critical re-envisioning is necessary to avoid blind application of theories that are based on these assumptions. Second, through summarizing prior research on negotiations as a specific form of buyer-seller interactions, we delineate the implications of the informational and technological shifts for broader buyer-seller interactions. Our articulation and detailing of these implications result in a cohesive conceptual framework that unpacks the critical pathways through which informational and technological shifts not only enable but also alter buyer-seller interactions. By highlighting findings in adjacent fields that can inform marketing research on buyer-seller interactions, we also expand the breadth of the domain in meaningful ways. Third, we identify several useful avenues to guide future research on and practice of buyer-seller interactions.

Our research agenda not only identifies interfirm and firm-level research opportunities but also identifies several substantive research questions related to sales management and personal selling. Taken together, our focus on dyadic and multiadic exchange complements macro and monadic perspectives in recent empirical and conceptual work on technology-enabled interactions in digital environments (Köhler et al., 2011; Lemon \& Verhoef, 2016; Moffett et al., 2020; Singh et al., 2019, 2020; Yadav \& Pavlou, 2014, 
2020). Our contributions are at the level of relationships and theory, unpacking how these shifts fundamentally change the relationships among important constructs in the domain of buyer-seller interactions and providing a useful road map for future research.

Our manuscript is organized as follows. First, we briefly review the nature of the informational and technological shifts. This is followed by a survey of seminal and recent frameworks on buyer-seller interactions, which allows us to pinpoint the gaps in these frameworks regarding the recent changes. Next, we present an overview of learnings from research on negotiations, a specific form of buyer-seller interactions, which sheds light on the impact of these shifts on buyer-seller interactions in general. We provide specific insights from the negotiation literature and conclude with a future research agenda.

\section{Informational and technological shifts}

Buyer-seller interactions have undergone drastic changes in the past decade due to the two main forces that have altered buyers and the way they approach and interact with sellers. The first major force - the availability of valuable information to buyers-has created powerful and better-informed customers. These customers are more knowledgeable about their options, are more certain about what they want and how much they should pay for it, typically engage the seller late in their buying journey when they are close to making a decision, are less patient with the seller, and are tougher in negotiations (Ahearne et al., 2019a, 2019b; Zettelmeyer et al., 2006). We refer to the shifts from information asymmetry to increased information symmetry between buyers and sellers as "informational shifts." The second major force affecting buyer-seller interaction is the emergence of new technologies in recent years that have reshaped the interface between firms and customers. We refer to this change as "technological shifts."

\section{Information shifts: from information asymmetry to increases in information symmetry}

The notion that buyers are less informed than sellers has been a central premise of the large body of research on buyer-seller interactions (Bazerman \& Neale, 1993; Mishra et al., 1998; Samuelson, 1984). Buyers have typically been deemed less informed about their options, the true value of the product, or the reservation price of the seller (Pinkley et al., 1994; White \& Neale, 1991). At least three informational shifts in buyer-seller interactions challenge the assumption of information asymmetry. These include buyers' greater access to information about the counterpart, awareness of substitutes, and connections with other customers. $^{1}$

\section{Information about the counterpart}

Buyers today can access a great deal of information about sellers, including competitors' offerings. In many cases, buyers no longer rely on sellers' salespeople for information about products and services (Hartmann et al., 2018). In the automotive industry, for example, dozens of third-party platforms (e.g., Edmunds, TrueCar, Autotrader) not only reveal the average price paid for a model in a given region but also expose dealers' cost (i.e., factory invoice price). For industrial machinery products, similar cost information exists across websites, such as machineseeker.com, IronPlanet. com, and Buyerzone.com. Similarly, commercial/residential improvement buyers can find this information on websites such as Fixr.com or CostOwl.com, and B2B software buyers can consult Capterra.com, Needto.com, and similar sources. As a result, buyers who do their homework can gain rich information about a product's true market value and the seller's reservation price.

On the other hand, advances in technologies and analytics have made it possible for firms to know more about their buyers, both existing and prospective. Sellers can now design their sales process in a way that captures customer data in each step of the customer journey, and can even intentionally introduce unpredictability into the customer journey to enhance customer engagement (Lemon \& Verhoef, 2016; Neslin et al., 2006; Siebert et al., 2020; Verhoef et al., 2009). However, this latest trend of opportunities created by the information revolution is not devoid of challenges for firms. Whereas the majority of buyers are more knowledgeable than before due to product and pricing comparison websites that permeate almost every industry, sellers' abilities to use big data vary (Mikalef et al., 2020). Transforming customer data into knowledge-in-use requires significant investments in data acquisition and assimilation capabilities and the capacity to move to a data-driven culture (Lam et al., 2017). Moreover, the push to protect customer privacy and new legal obstacles such as the General Data Protection Regulation in Europe hamper sellers' ability to utilize big data to the fullest (Martin et al., 2017). Thus, the big-data advantage does not necessarily reestablish sellers' traditional edge over buyers, a notion at the center of the information asymmetry literature.

\footnotetext{
1 Access to information, however, does not guarantee that customers have greater knowledge about these; knowledge requires internalization and endowing information with meaning (Glazer, 1991; Lam et al., 2017).
} 


\section{Awareness of substitutes}

Buyers can also conduct research on options and substitutes before negotiations. Various websites include comparisons of options as one of the differentiating features to attract users. For example, B2B software buyers can compare various options on websites, such as softwareadvice.com, to narrow down their research to options that better fit their preferences before initiating a formal interaction with the seller. Rich information on competing offers across various industries puts customers in a more advanced stage of the buying process before they even contact a seller (Ahearne et al., 2019b; Rapp et al., 2014).

\section{Connections with other customers}

Customer-to-customer (C2C) connections can take various forms, ranging from word-of-mouth to helping each other (Thompson et al., 2016; Yadav \& Pavlou, 2014). Customers who leverage these connections are more informed about their alternatives and the prices paid by other customers, which reduces information asymmetry in their interactions with sellers. Note, however, that connections with other customers represent just one of many avenues through which a customer can acquire information. For example, customers can explore competitors' websites without consulting other customers. Nevertheless, verified online reviews, customer forums, and many other online resources brought about by the information revolution have elevated the informational value of $\mathrm{C} 2 \mathrm{C}$ connections.

\section{Technological shifts: from face-to-face to technology-enabled interactions}

In the past two decades, the digital technology revolution has given rise to three major changes, including new interaction media, the multiplicity of buyer-seller interactions, and new interaction-support technology. Unlike in-person interactions, electronically-mediated interactions can create a context in which buyers and sellers are more distant and unknown (Thompson, 2006). In addition to visual cues such as body language, facial expressions, and gestures, being in the same place at the same time can lead to a feeling of a shared place (Thompson, 2006). Moreover, unlike face-toface interactions, which are contemporaneous, some electronic modes of communication such as email are asynchronous. This means that a buyer might need to wait to receive a response from a seller when he or she is communicating via email or other asynchronous media (Singh et al., 2020). The absence of visual facial and social cues (e.g., nodding) or other visible agreement signals makes asynchronous communication more difficult. We briefly discuss these changes next.

\section{New interaction media}

Buyers and sellers today can interact through a range of channels made possible by technology. While relatively older media, such as email, telephone, and voice mail, have been around for quite a while, and a considerable amount of research exists on these media, research on newer technologies such as video conferencing is scant (Khan \& Ebner, 2019). In fact, the use of online agents as virtual employees to socialize new customers is quite new to the field (Köhler et al., 2011). In addition, older media such as phone-based Short Message Services are undergoing revolutionary changes, expanding to app-based messaging such as WhatsApp, WeChat, Facebook Messenger, LinkedIn InMail, Twitter, and TikTok.

\section{Multiplicity of media in buyer-seller interactions}

While face-to-face remains the preferred mode of interaction, multiple media can be used during different stages of the interaction (Moffett et al., 2020). For example, simple logistical tasks can be handled through email, sensitive or relational communication can remain face-to-face, and video conferencing can satisfy urgencies that might arise in certain stages of the interaction.

\section{New interaction-support technology}

New interaction support systems can help mitigate the vagueness of human communications by providing structure as well as offering advice during the interaction. In the case of the former, the system can ask buyers to enter specific information, to which the other party can respond (Khan \& Ebner, 2019). In the latter case, support systems can offer advice based on what the system has learned from previous interactions. Sellers can also leverage conversational agents to learn more about buyers (Thomaz et al., 2020).

\section{Existing frameworks of buyer-seller interactions}

\section{Seminal frameworks: focusing on communication and roles}

Sheth's (1975) seminal framework of buyer-seller interactions draws on communication theories. Accordingly, the framework focuses on two key elements, communication content (i.e., the reason for the interaction) and communication styles (i.e., formats, rituals, or mannerisms that the buyer and the seller adopt in their interaction). This 
framework emerged when most buyer-seller interactions were primarily face-to-face and characterized by information asymmetry favoring the seller.

Broadening the scope of inter-organizational exchange behavior in marketing channels, Frazier (1983) extends Sheth's (1975) framework from a focus on communication processes to three interrelated processes: initiating, implementing, and reviewing. The initiation process focuses on why and how firms seek to initiate exchange relationships within marketing channels, which in turn determine the roles, power, and aspirations that will influence the implementation process. During the implementation stage, roles are enacted, and influence is exerted. As a result, cooperation and/or conflict arise, leading to rewards or losses. In the last stage, the review process, exchange partners evaluate these rewards or losses. ${ }^{2}$

In the services marketing domain, Solomon et al. (1985) draws from role theory to conceptualize the dyadic interaction between a service provider and a customer (i.e., a service encounter) as role performance. Specifically, Solomon et al., (1985: 109) posit that "the setting the organization provides, together with the implicit and explicit cues it gives service employees, helps determine the content of the employee role, which in turn, has an impact on and is affected by the customer role." These three frameworks unpack the communication foundations of buyer-seller interactions and emphasize the importance of roles, goals, and aspirations in determining the relational and instrumental outcomes of the interaction. However, it remains unclear how these foundations change as a result of the informational and technological shifts and the ramifications of such changes on the interaction processes and outcomes.

\section{Recent frameworks: focusing on technologies and customer journey}

\section{Technology-mediated interactions}

In their review of computer-mediated marketing environments, Yadav and Pavlou (2014) delineate four types of interactions: customer-firm, firm-customer, customer-customer, and firm-firm. After reviewing research in various domains, including network navigations, search engines, recommendation systems, online advertisements, pricing, multichannel decisions, social networks, online reviews, inter-organizational networks, competition, and B2B auctions, they conclude that marketing research still lags behind

\footnotetext{
${ }^{2}$ Although Frazier (1983) discussed these rewards and losses in terms of intrinsic and extrinsic aspects, these rewards and losses can be reframed in relationship marketing frameworks as relational issues (e.g., trust, commitment, Morgan \& Hunt, 1994) and instrumental perspective (e.g., expertise, profits).
}

practice in several respects. Furthermore, the special issue on "The Future of Technology in Marketing" published in the Journal of the Academy of Marketing Science in 2020 includes several articles on artificial intelligence, mobile marketing, in-store technologies, social media, and digital customer orientation (Grewal et al., 2020). Research in sales has also mapped out several new research avenues that focus on the impact of digitization and AI technologies on personal selling (e.g., Singh et al., 2019). These frameworks focus primarily on either customers' perspectives or sales force management issues.

The majority of these articles and frameworks focus on technologies as a means (i.e., technologies as enablers of buyers and sellers' behavior, or how buyers and sellers prefer to interact) rather than the cause of the fundamental changes in buyer-seller interactions (i.e., why buyers and sellers now interact differently). As a result, how technologies influence interactions remains a black box (Yadav \& Pavlou, 2014). Furthermore, the primary focus is on B2C interactions, leaving B2B interactions understudied. In this research, we divert from this focus and extend recent research by Moffett et al. (2020) that we review next.

\section{Technology and multi-format communication}

Drawing from communication theories, Moffett et al. (2020) propose a characteristic-level framework to study multi-format communication strategies. The framework unpacks the black box by delineating how six characteristics of communication via different technologies influence firm performance, with communication outcomes (i.e., effectiveness, efficiency, and experience) as the underlying mechanisms. In so doing, these authors view technologies as determinants rather than mere enablers of buyer-seller communication outcomes. However, the authors focus specifically on communications rather than interactions. Conceptually, communication is a specific form of interaction to exchange information, while interaction implies a reciprocal action or influence (Brown \& Lee, 1994). Furthermore, although Moffett et al. (2020) provide deep insights into how multiformat communication technologies influence communication outcomes, they have not fully captured how those technologies impact fundamental issues of buyer-seller interactions such as buyers and sellers' roles, power, and aspirations that may precede communication outcomes in both $\mathrm{B} 2 \mathrm{C}$ and $\mathrm{B} 2 \mathrm{~B}$ interactions.

\section{Customer journey and online relationship}

In recent frameworks on customer journeys and online relationship formation, researchers have explored topics such as web page design, online word of mouth, customer privacy, trust, security, and customer switching behavior between 
different channels (e.g., Bleier et al., 2019; Grewal et al., 2020; Lemon \& Verhoef, 2016; Neslin et al., 2006; Steinhoff et al., 2019; Van Doorn et al., 2010; Verhoef et al., 2009). These frameworks have touched on the role of information from different angles, theorizing how firms can use information generated from customer touchpoints to enrich customer experience and how firms can strategically communicate product- or brand-related information via public relations efforts in order to increase customer engagement (Lemon \& Verhoef, 2016; Van Doorn et al., 2010).

However, an arguably more important type of information is created by tens, if not hundreds, of third-party websites and online resources that are outside the control of sellers and help customers better understand their options and how much they should pay for their desired products (e.g., usergenerated content on online communities, third-party review platforms; Yadav \& Pavlou, 2014). This type of information significantly alters different phases of customers' journeys, which have important consequences for their interactions with the firm. For example, in their theoretical work, Lemon and Verhoef (2016) use the traditional classification of prepurchase, purchase, and post-purchase phases of the customer journey and explain how different customer-brand touchpoints can enhance customer experience. With more independent information at their disposal, buyers might choose to do their research first and detest firm-initiated communications. They engage with the seller much later in the buying cycle, which limits the effectiveness of firms' interaction strategies traditionally used across touchpoints. As a result, existing theories of buyers that place emphasis on customer uncertainty and customer lack of awareness of sellers or offerings [e.g., Kahneman and Tversky's (1979) prospect theory, McGuire's (1969) hierarchy of effects model] need revisions to fully reflect modern buyers' characteristics.

\section{The impact of informational and technological shifts on buyer-seller interactions: insights from negotiation research}

Our review framework, summarized in Fig. 2, integrates two seemingly unrelated streams of research on the informational and technological shifts to unpack how these shifts lead to fundamental changes in buyer-seller interactions: (1) change in buyers' and sellers' roles, power, and aspirations and (2) change in information processing. Together, these two changes have three implications for (1) the seller's effectiveness, (2) the buyer's attitude and behavior, and (3) their interactional processes (i.e., relational and solutiondeveloping processes). In our framework, roles refer to responsibilities and expectations, power refers to authority and dependence, and aspirations refer to goals and motivations (Frazier, 1983). Information processing refers to the way sensory organs feed the brain information about the environment and how the brain interprets this information (Lindsay \& Norman, 2013).

To illustrate these changes, we draw from insights from buyer-seller negotiation research. We focus on buyer-seller negotiations because they represent one of the most important forms of buyer-seller interactions in which both the buyer and the seller have aspirations to enter into a transaction with financial implications for both, whereas non-negotiation interactions may not necessarily result in a sales deal (e.g., Perdue \& Summers, 1991). Based on these insights, we develop an agenda for future research on buyer-seller interactions. To this end, we provide a summary of prior research on informational and technological shifts in negotiations in Tables 1 and 2, respectively. Where possible, we distinguish between non-marketing and marketing outlets to underscore the research gaps in marketing literature and inform scholars of useful research in non-marketing literature on these issues. As the tables show, marketing research on the implications of these shifts is still sparse. Furthermore, outside the marketing domain, there is also a dearth of research on the impact of increases in information symmetry.

\section{Impact of informational and technological shifts on roles, power, and aspirations}

\section{Sellers' reduced educational role}

In the age of high levels of information asymmetry, it was possible for the seller to educate the customer about different features and benefits of the product or service either before or during the negotiation. A successful connection built with the customer during the product demonstration stage, as the salesperson helped the customer narrow his or her search, could help the seller in subsequent negotiations (Heiman \& Muller, 1996). This dynamic has drastically changed, with customers showing a reduced appetite for product information and demonstrations due to their own in-depth research before interacting with sales reps (Ahearne et al., 2019b; Hartmann et al., 2018).

Many industries are now reporting statistics about the customer buying process, indicating an increasingly dwindling role of salespeople in helping customers narrow their search. Evidence from the automotive industry, for example, reveals that the average buyer completes 1.9 test drives before making a decision, with $55 \%$ completing only one test drive and, according to some reports, as many as $20 \%$ making a final decision without a test drive. Buyers who complete at least one test drive are reported to make their final purchase decision under 30 min (DMEautomotive, 2014; Gorzelany, 2014). Almost all car buyers extensively research 
Table 1 Prior research on increases in information symmetry in negotiations

\begin{tabular}{|c|c|c|}
\hline Theme & Representative negotiation research & Summary of findings \\
\hline $\begin{array}{l}\text { Increases in information } \\
\text { symmetry } \rightarrow \text { Roles, power, } \\
\text { aspirations, and behavior }\end{array}$ & $\begin{array}{l}\text { Ahearne et al., (2019a, 2019b), Atefi et al. (2020), } \\
\text { Ratchford et al. (2003) and Zettelmeyer et al. (2006) }\end{array}$ & $\begin{array}{l}\text { Product demonstration backfires to customers who } \\
\text { already know what they want } \\
\text { Increases in information symmetry creates an opportu- } \\
\text { nity to build trust, as informed buyers can more easily } \\
\text { verify the word of the salesperson and the information } \\
\text { communicated to them during the interaction } \\
\text { Salesperson's role in customer provision has changed } \\
\text { since concealing information is no longer effective. } \\
\text { Instead transparency might work better } \\
\text { Customers are now more powerful, with more informa- } \\
\text { tion on both the true value of a product as well as their } \\
\text { other options; gives them more "walk away" power } \\
\text { Challenging informed buyers more easily leads to losing } \\
\text { them } \\
\text { Informed customers drive the agreed-on price down, } \\
\text { leaving less margin for the seller }\end{array}$ \\
\hline $\begin{array}{l}\text { Increases in information } \\
\text { symmetry } \rightarrow \text { Buyer-seller } \\
\text { interactional processes and } \\
\text { outcomes }\end{array}$ & $\begin{array}{l}\text { Atefi et al. (2020), Blanchard et al. (2018) and Mohan } \\
\text { et al. (2020) }\end{array}$ & $\begin{array}{l}\text { Sellers' cost transparency with informed buyers captures } \\
\text { their trust } \\
\text { Bundling the negotiated product to add-on and aftermar- } \\
\text { ket products or services offered by other profit centers } \\
\text { within the firm that retain their information advantage } \\
\text { can reduce the negative impact of negotiating with } \\
\text { informed customers } \\
\text { Unconventional strategies such as referrals to a competi- } \\
\text { tor for non-focal products can earn customers' trust }\end{array}$ \\
\hline
\end{tabular}

We are not aware of non-marketing empirical studies on the impact of increases in information symmetry

across more than 15 third-party websites, spending an average of $62 \%$ of their entire car-shopping time online before spending the rest of the time at dealerships (Cox Automotive, 2019). Moreover, more than $60 \%$ of customers have already made up their minds about the model they want to buy before they enter a dealership (Morrissey et al., 2017). Similar statistics exist in other industries. For example, HubSpot's study of more than 500 global customers reports that only $19 \%$ of B2B buyers connect with a sales representative when they want to learn about a company's product or service (An, 2016). This study also shows that $80 \%$ of buyers contact a salesperson only after they have at least shortlisted their consideration set (i.e., have a fairly good idea of what they want to buy). These statistics are line with the notion that the buying journey is shortened and sellers are likely to get involved only in the later stages of the customer journey.

These pieces of evidence suggest that salespeople's role in educating customers has become limited, given that an overwhelming number of customers are rather close to making, if not have already made, their final decision before they see a salesperson. This leaves little room for salespeople to try to influence the outcome of the negotiation by making a connection with the customer during the demonstration phase. Recently, Ahearne et al. (2019b) found that product demonstrations to customers who already know what they want can even backfire, reducing purchase likelihood and customer satisfaction.

\section{Sellers' role in information provision}

Traditional bargaining and negotiation research had consistently shown that when buyers have less information than sellers, they are always worse off (Chatterjee \& Samuelson, 1983; Samuelson, 1984; White \& Neale, 1994). By contrast, when buyers can glean sensitive information about the seller, such as the reservation price or the product cost, they can significantly improve their outcomes (Morton et al., 2011; Pinkley et al., 1994; White \& Neale, 1991, 1994). As a result, there is a consensus among scholars that sellers must protect sensitive information such as their reservation price from leaking to buyers because such revelations could significantly weaken their bargaining position (Bazerman \& Neale, 1993; Chatterjee \& Samuelson, 1983; Samuelson, 1984).

The information revolution has undermined some of these established conclusions. With the availability of more information, sellers might find that withholding this information might be less valuable than disclosing it in a way that signals benevolence and captures customers' trust (Atefi et al., 2020). Research has also documented the salutary effects 


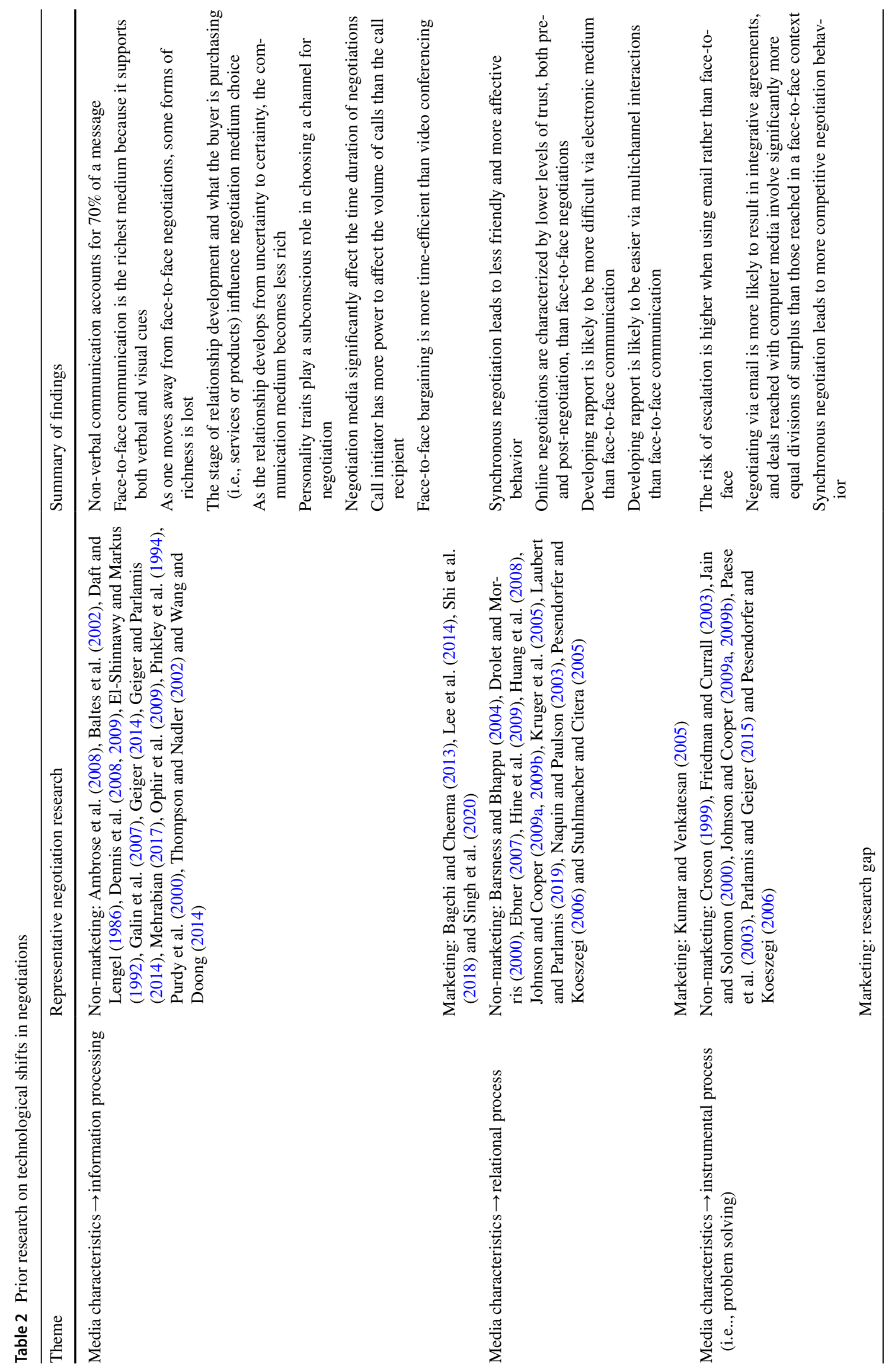


of transparency and cost disclosure in other non-negotiated buyer-seller interactions (e.g., Mohan et al., 2020).

\section{Buyers' increased bargaining power}

One of the main sources of power imbalance in negotiations is information asymmetry. Information asymmetry provides an opportunistic seller the chance to employ competitive strategies to maximize its own payoff. Under asymmetric information, it is costly for buyers to determine the true value of the product or the merits of the deal. For example, a used car buyer might need to bring a mechanic to evaluate the value of a car, a merger or acquisition deal will not go through without the counsel of expensive consulting firms, channel members need to purchase market intelligence and research reports, and homebuyers rely on inspectors and appraisers to close the deal (Brett \& Thompson, 2016; Samuelson, 1984; Srivastava \& Chakravarti, 2009). The costly nature of buyers' fact-checking and information gathering allowed sellers to play offense, using aggressive strategies to steer the deal toward a favorable outcome for themselves (White \& Neale, 1994). Starting from a high initial offer was one such strategy, as the less-informed buyer would take the initial offer as a cue for the true value of the product and counter with an offer that might have still been much higher than the seller's reservation price (Galinsky \& Mussweiler, 2001).

The decline in buyer-seller information asymmetry has created a major challenge for sellers in terms of the outcome of the negotiation. Facing knowledgeable customers who have done their research prior to the negotiation, sellers are finding their margins diminishing (Zettelmeyer et al., 2006). This is in line with traditional predictions of economic and marketing theories that as parties gain more information about their counterpart, they can extract a higher payoff from the negotiation (Chatterjee \& Samuelson, 1983; McGinn \& Wilson, 2004). Beyond information about the seller's cost and reservation price, buyers are also more informed about the availability and relative desirability of other options, which makes their best alternative to a negotiated agreement (BATNA) more salient (White \& Neale, 1991, 1994). BATNA, or the "walk-away" outcome, is widely recognized as a source of relative power in negotiations because the party with a stronger BATNA can enforce its desired outcome with a take-it-or-leave-it approach (White et al., 1994). With a wider range of options brought to their attention on the Internet, buyers are in a stronger position at the negotiation table.

\section{Changes in buyers' aspirations}

The availability of sellers' reservation prices, competitors' prices, and online price evaluation services, which suggest ballpark prices for given products or services, create price references for buyers. While information asymmetry allowed sellers to be tough on price and apply distributive strategies geared toward getting the most out of the uninformed buyer, increases in information availability has shifted the power to buyers (Ahearne et al., 2019a). Evidence suggests that buyers now arrive at negotiations when they are close to certain about their final choice and acceptable price range (Ahearne et al., 2019b). This certainty, in turn, can influence what they hope and expect to achieve from the negotiation (Siegel \& Fouraker, 1960).

Prior research has shown that negotiators with higher aspirations are more demanding, less lenient, and less willing to yield to the opposing party (Hüffmeier et al., 2014; Thompson, 1995). Recent findings indicate that challenging these buyers might have serious consequences, as those with higher certainty about their desired deal are more likely to leave the negotiation and report dissatisfaction with the interaction when they are challenged by the salesperson (Ahearne et al., 2019b). Moreover, rejecting undesirable offers has become easier in negotiations, as several platforms (e.g., eBay) have options for automatically filtering out offers or counteroffers that do not fall within the userdefined range of acceptable offers (Backus et al., 2020).

\section{Changes in sellers' aspirations}

These changes have also affected sellers' negotiation aspirations. Salespeople who negotiate with a less flexible customer face the trade-off between defending the price or losing the deal (Alavi et al., 2018). With more customers demanding higher discounts and tougher terms, the opportunity cost of toughness with the customer is amplified, as the next customer will likely demand the same level of concessions. According to prior studies, losing consecutive deals forces salespeople to be more lenient in negotiations and give larger and more frequent discounts to customers (Boichuk et al., 2014). Therefore, the shift from asymmetry to increased symmetry prompts sellers to lower their negotiation aspirations and adjusting their behavior to more lenient strategies.

\section{Impact of informational and technological shifts on information processing}

The shifts in negotiation media have important implications for buyer and seller behavior. As Table 2 shows, we discuss these implications along three dimensions of negotiation: information processing determined by medium richness, information processing determined by medium interactivity, and information coordination during multimodal negotiations (Barsness \& Bhappu, 2004; Daft \& Lengel, 1983, 1986; Moffett et al., 2020). 


\section{Media richness and information processing}

During negotiations, various cues are exchanged and processed. These cues include visual communication cues (e.g., body language, facial expression, gestures, posture), vocal communication cues (e.g., tone, pitch, rate, intonation, pace of speech), personal appearance (e.g., clothing, grooming, accessories), and physical space (e.g., setting). Prior research has primarily relied on medium richness theory to explain the impact of cues. Originally developed without considering newly developed media, medium richness theory has been retrofitted to explain the effects of new media (e.g., El-Shinnawy \& Markus, 1992). Medium richness indicates the degree to which a medium is able to communicate contextual cues. Face-to-face communication is deemed the richest medium because it supports all these cues. As parties move away from face-to-face negotiations, they begin losing some richness (Daft \& Lengel, 1986). For example, in video conferencing, parties lose the ability to see each other's body language, and in text-based interaction such as email, they lose both vocal and visual cues. As a result, video conferencing ranks as the next richest media, followed by email. Text messaging ranks as the least rich medium of all.

Research shows that verbal content accounts for $30 \%$ of a message, while non-verbal communication accounts for the other $70 \%$ (Mehrabian, 2017). Thus, interaction technologies that deprive buyers and sellers of these non-verbal communication cues-voice, body language, and appearance-can significantly modify and shape buyer-seller interaction dynamics and outcomes. For example, richer information about verbal and nonverbal cues in face-to-face interactions can be counteractive, because the effectiveness of FLEs' problem solving work might be impaired by relational work and affect display (Marinova et al., 2018). Although e-negotiations can be effective in influencing buyers, experienced salespeople with proven sales performance in traditional interfaces (e.g. face to face, phone) may have trouble reading buyer's mindset in e-communications, reducing the likelihood of contract award (Singh et al., 2020).

Scholars have also examined the impact of interaction setting on information processing. For example, research shows that online negotiators do better when they use a larger screen (Naquin \& Paulson, 2003). Using data from eBay auctions and the lab, Bagchi and Cheema (2013) show that a red background elicits higher bids than a blue background. By contrast, red backgrounds decrease price offers in negotiations, eliciting different aggression levels. Similarly, Lee et al. (2014) explore how the presence or absence of color affects information processing. They show a differential impact of black-and-white versus color imagery on the construal level.

\section{Media interactivity and information processing}

Media interactivity refers to the degree to which a medium is able to convey an instantaneous flow of information between negotiators. Interactivity has two scopes: synchronicity and parallel processing. Face-to-face interaction, video conferencing, and telephone calls are synchronous; each party hears the message in real-time (Dennis et al., 2008, 2009). By contrast, emails are asynchronous. Parallel processing refers to a medium's capacity for concurrent message communication. Face-to-face negotiations include parallel processing in the sense that negotiators can process what they and the other party have said simultaneously. When negotiators move away from traditional face-to-face negotiations, they both transmit and receive information differently. Drawing upon behavioral coordination, Moffett et al. (2020) suggest that the format should match the message for each task, rather than the interaction as a whole. Specifically, when the focus is on message convergence, such as ambiguous information, synchronous media are more suitable. However, when message conveyance is more important, such as unambiguous information, asynchronous media can be used as well.

\section{Information coordination in multimodal negotiations}

Negotiators may use email, video conferencing, and text messaging during different stages of negotiation. Information coordination is the ability of negotiators to agree on a course of action that results in a particular outcome (Thompson \& Nadler, 2002). When firms engage in multimodal negotiations, the need to coordinate information across these media becomes essential. First, in the digital age, a huge amount of information is available to negotiators. As a result, it has become difficult for the parties involved to filter out irrelevant information. Furthermore, negotiators are easily distracted and have low recall (Ophir et al., 2009), which makes it essential to coordinate which data they need to share at each stage. Second, in electronic negotiations, emails in particular, negotiators are more likely to suspect their counterpart of lying, and that perception exists even when no deception is committed (Thompson \& Nadler, 2002). As a result, negotiators need to monitor the information being shared to resolve potential misunderstandings.

\section{Implications of the shifts for buyers and sellers' interactional processes}

Because of the two shifts and the fundamental change in the buyer and seller's roles, power, and aspirations, and information processing, several elements of buyer-seller interactional processes and outcomes have also changed. In this section, we review empirical evidence pertaining 
to the change in (1) buyers' attitude and behavior, (2) sellers' effectiveness, and (3) interactional processes, including trust-building and solution development.

\section{Buyers' attitude and behavior}

As mentioned before, overwhelming evidence suggests that the phases identified in customer journey research are undergoing major changes as a result of more informed and certain customers. Specifically, the purchase phase has significantly shortened, and the importance of customer touchpoints during this phase via product demonstration and education has diminished as more certain customers engage the seller only when they want to finalize the deals for which they have done their homework during the pre-purchase stage (Accenture, 2014; Ahearne et al., 2019b). These customers arrive at the negotiation table with a different attitude and behave differently. With more information on the true value of the products and the seller's reservation price, they know what to ask for. With a higher "walk-away" power due to their knowledge, they can be more assertive during negotiations.

Regarding the medium of interaction, media with less richness than face-to-face reduce the impact of non-verbal cues that facilitate mutual understanding and ease the negotiation process (McGinn \& Wilson, 2004). As a result, in negotiations over chat or emails, customers might feel a lack of control, higher vulnerability, and insecurity about the underlying motives of the faceless seller (Yang et al., 2009). Media with less interactivity, such as emails, will allow the buyer to ponder before responding, fact-check the seller's claims, and respond at will (Singh et al., 2020).

\section{Seller's effectiveness}

These changes in buyers' attitudes and behaviors reduce the effectiveness of some traditional and some more recent selling paradigms. Frameworks such as the challenger sales model (Dixon \& Adamson, 2011) that promote a purposeful generation of tension with customers to increase engagement and spark new ways of thinking are most likely going to backfire due to informed customers who are more certain about their choices (Ahearne et al., 2019b; Rapp et al., 2014). Using traditionally advocated competitive strategies such as starting from a really high offer to anchor the counteroffer might not be effective either, due to customer's knowledge about the true value of a deal, and might lead to losing the deal. In general, with more powerful buyers, competitive negotiation strategies are proving less effective and might soon be replaced by more transparent, honest, and cooperative strategies such as the ones studied in recent research (Atefi et al., 2020; Blanchard et al., 2018; Mohan et al., 2020). Moreover, the powerful customer is driving the margins of the main interaction down, and hence sellers might pursue a different value proposition, as we allude to later in the paper.

In addition, many tactics that are effective in face-toface interactions do not readily translate into other modes of interaction that are enabled by technology. Approach, rapport-building, communication skills, and many other traditional constituents of a successful sales interaction are affected by the medium of interaction. Even videoconferencing interfaces such as Zoom or Skype that are still high in medium richness are restricted in many ways compared to face-to-face interactions. Eye contact, an important element in building rapport and connecting with the customer, is not possible in this medium, as it requires the display screen and the camera to be in the same spot. The restriction of the picture to head and shoulders eliminates a lot of nonverbal cues used by sellers to influence buyers. On the other hand, these new media offer additional options over face-to-face interactions, such as the ability to view yourself and correct your facial expressions, which might benefit sellers. In sum, new selling strategies are going to emerge to respond to informational and technological shifts, which offer new areas for research.

\section{Relational processes}

We refer to the dynamics of trust-building and affective processes in buyer-seller negotiations as relational processes. First, in terms of trust-building, while the informational shifts have created more powerful customers, they also present a unique opportunity to capture customer trust (Atefi et al., 2020). Under traditional information asymmetry, trust building was difficult since buyers had no way to verify sellers' claims (Doney \& Cannon, 1997; Srivastava \& Chakravarti, 2009). Such difficulty in trusting the seller hampered the effectiveness of the interaction, reduced the likelihood of reaching a deal, and lowered satisfaction with the outcome (Galinsky et al., 2002; White et al., 1994). With the prevalence of information prior to and during a negotiation, sellers can more easily earn customer's trust since customers can corroborate the truthfulness of their words.

In terms of technological shifts in buyer-seller interactions, face-to-face interactions result in social bonds that are likely diminished in electronic modes of interaction (Weisband \& Atwater, 1999). In these modes, parties represent unknown entities, which causes ambiguity in understanding the other party's traits and characteristics. However, as the other party becomes less abstract, he or she is perceived as more alike, which also influences the other party's judgments (Small \& Loewenstein, 2003). Furthermore, building trust in face-to-face interactions is easier (Paese et al., 2003). Compared with face-to-face negotiations, online negotiations are characterized by lower levels of trust (Huang et al., 2008; Naquin \& Paulson, 2003). In addition, 
face-to-face contact fosters rapport building, which in turn helps negotiators coordinate on mutually beneficial settlements (Drolet \& Morris, 2000). Another reason for mistrust is the lesser felt compulsion to share accurate information. Researchers have shown that when information is shared electronically, it is much more likely to be inflated or misrepresented in some way (Citera et al., 2005). E-negotiators perceive their opponents as less credible than face-to-face negotiators and are also more likely to be dishonest themselves (Citera et al., 2005). Negotiators who communicate through richer media such as video calls have reported higher levels of trust and satisfaction than negotiators who interact via text (Naquin \& Paulson, 2003).

Second, technological shifts also influence affective processes. Emotions and their valence are more complex to understand correctly or to convey consistently in textbased negotiations (Laubert \& Parlamis, 2019). Computer mediation reduces the amount of emotion communicated, which in turn decreases the likelihood of agreement (Johnson $\&$ Cooper, 2009a). Without the benefit of non-verbal cues, conveying emotions over electronic media such as email can be difficult. Research shows that this difficulty is often underappreciated, and negotiators tend to believe that they can communicate over email more successfully than they actually can (Kruger et al., 2005). Media synchronicity also influences affective processes. Synchronous negotiation leads to less friendly and more affective behavior. In asynchronous negotiations, negotiators exchange more private and task-oriented information and are friendlier (Pesendorfer \& Koeszegi, 2006). Moreover, while using lean channels, negotiators tend toward logical argumentation and fact-based presentation rather than emotional or personal appeals (Barsness \& Bhappu, 2004). This could be bad news for sellers who rely on emotional appeals in their persuasion tactics. Finally, media multiplicity, the use of multiple media to engage with counterparts, can also increase rapport and loyalty. Prior research shows that using multiple channels enhances customer loyalty (Kumar \& Venkatesan, 2005; Steinhoff et al., 2019; Thomas \& Sullivan, 2005). This is attributed to the increased interaction between buyers and sellers, which facilitates deeper relationships (Wallace et al., 2004).

\section{Instrumental processes: negotiation processes and outcomes}

We refer to the process of determining the outcome of negotiation as instrumental processes. Increases in information symmetry plays an important role in how buyers and sellers negotiate the terms. In particular, while prior research on information asymmetry finds that sellers often start from a competitive position (Adair \& Brett, 2005; Brett \& Thompson, 2016), it is obvious that using distributive strategies featured in prior literature to get the most out of the customer interaction might not be effective in dealing with today's informed customers. Much less obvious is how technologies can influence negotiation processes and outcomes, an issue we will focus on in this section.

First, synchronous media reduce the time required to finalize a negotiation (Galin et al., 2007). Purdy et al. (2000) find that face-to-face bargaining is more timeefficient than video conferencing. Similarly, Baltes et al.'s (2002) meta-analysis comparing face-to-face and computer-mediated communications suggests that the latter increase the time required to complete tasks compared with the former. Second, communications theory suggests that the medium affects negotiation style as well as the type and the extent of information that the negotiators share, which in turn influences the process of developing solutions (Khan \& Ebner, 2019; Thompson, 2006). Importantly, computer mediation decreases the likelihood of agreement (Johnson \& Cooper, 2009a), and the risk of escalation increases when in email vs. face-toface interactions (Friedman \& Currall, 2003). However, while the effectiveness of face-to-face negotiation is significantly greater than electronically mediated negotiation (Jain \& Solomon, 2000), electronic media do not always disadvantage the e-negotiator (Parlamis $\&$ Geiger, 2015). For example, negotiating via emails is more likely to result in integrative agreements, and deals reached through computer-aided media often involve more even division of surplus than those reached in a face-toface context (Croson, 1999). In addition, synchronous negotiation leads to more competitive negotiation behavior (Pesendorfer \& Koeszegi, 2006). Differences also exist in electronic media. Telephone and email both induce competitive negotiation behavior, but honest disclosure suppresses the competition that arises in remote media (Paese et al., 2003).

Third, media type influences the satisfaction with the solution. Specifically, Baltes et al.'s (2002) meta-analysis suggests that computer-mediated communication leads to lower satisfaction than face-to-face communication. In an extensive review, Geiger (2014) reports that because parties negotiating in text-based media develop more realistic aspirations and use more explicit relationship-building communication, they experience greater negotiator satisfaction than they do compared to face-to-face interaction. However, not all electronic media have the same effects. For instance, Purdy et al. (2000) find that face-to-face and video-conferencing conditions generate similar satisfaction levels. In addition, satisfaction with solutions requires a match between the medium and the goal. For example, Wang and Doong (2014) show that satisfaction is greater when using text-based systems to execute more analyzable tasks. 


\section{Research agenda}

Our review of buyer-seller negotiation research reveals that informational and technological shifts influence two key aspects of buyer-seller interactions: (1) roles, power, and aspirations and (2) information processing. Together, these factors alter buyer-seller interactional processes and outcomes. In this section, we extrapolate these insights about the impact of informational and technological shifts on negotiations to future research on buyer-seller interactions in general. Our research agenda, summarized in Table 3, includes three themes, namely (1) enriching the conceptual foundations of buyer-seller interactions, (2) examining change from the buyers' perspective, and (3) examining change from the sellers' perspective.

\section{Enriching the conceptual foundations of buyer- seller interactions}

We believe the first priority for future research is to first crystalize what scholars mean by buyer-seller interactions by developing a typology of buyer-seller interaction. Relatedly, it is important to revisit the conceptualization of buyer-seller information (a)symmetry to guide future theoretical development and empirical investigation of the impact of buyer-seller information (a)symmetry.

\section{Developing a typology of buyer-seller interaction}

Although existing frameworks of buyer-seller interactions (e.g., Frazier, 1983; Sheth, 1975) and newly developed frameworks of technology-mediated marketing are relevant to modern buyer-seller interactions (e.g., Lemon \& Verhoef, 2016; Moffett et al., 2020; Yadav \& Pavlou, 2014), our review of negotiation research clearly confirms that the dimensions of these interactions have fundamentally changed. While fundamental principles of buyer-seller interactions may still apply (e.g., interaction is a function of the characteristics of both parties and the situation, Kelley \& Thibaut, 1978), a systematic understanding of the dimensions of modern buyer-seller interactions and a typology of these interactions warrant immediate academic attention. Such a typology is beneficial in many ways. First, it would enable scholars to identify contingencies of existing theories and frameworks of buyer-seller interactions. Second, it would help researchers build on and extend research on buyer-seller negotiations to the specific type of buyer-seller interactions they are investigating. Third, it would provide a basis for related research on technology-mediated marketing, customer journeys, and online relationship marketing.
To develop these new frameworks, researchers need to systematically examine how buyer-seller interactions vary across five key dimensions: who, why, when, what, and how. First with respect to "who," even within the context of buyer-seller negotiation, buyer-seller interactions have changed from dyadic to "multiadic." At times, interactions might be monadic, in the sense that buyers may interact with sellers without sellers' knowledge and vice versa. On other occasions, customers may act in groups (shared buying, alliances, buying groups in B2B contexts, etc.) and engage with referrers and influencers (Eckhardt et al., 2019). Buyers and sellers may also interact anonymously in the Internet era. On the seller side, the first point of interaction might not be FLEs, and the seller might not always have identifiable information to fuse with non-identifiable data in order to map out the customer journey. Furthermore, the mixture of an automated and human social presence leads to more complex experiential processes, and the integration of employees' small data with firms' big data is not easy (Lam et al., 2017; Van Doorn et al., 2017).

Second, the purpose of buyer-seller interactions might not be solely to make a deal. As research on showrooming indicates, buyers may interact with sellers to extract information but purchase from another seller later (Kuksov $\&$ Liao, 2018). Interactions with sellers might have purely informational purposes, in which sellers' honest provision of guidance and referral, even if it does not lead to an immediate purchase, might increase the likelihood of future business (Blanchard et al., 2018). Third, regarding 'when', buyer-seller interactions may occur at any time during the customer journey. Research on multichannel consumers and the customer journey has just scratched the surface of these buyer-seller interaction aspects (Lemon \& Verhoef, 2016).

Fourth, with respect to "what," the content of the interaction might not be just about the focal offering. For example, as noted previously, the role of sellers and buyers in negotiations has changed as a result of informational and technological shifts. Further research could examine whether findings in negotiation research also generalize to other types of buyer-seller interactions. Fifth, the overlay of various interaction media and multichannel customers complicates 'how' buyers now interact with sellers. As reviewed previously, negotiation research provides good examples of how to explore this direction by drawing on media synchronicity and richness theories (Daft \& Lengel, 1983, 1986; Dennis et al., 2008; see also Moffett et al., 2020). Research on consumer use of websites also shows that trust is a key mediator between website characteristics and behavioral intent, but it is unclear whether this finding generalizes to other forms of interactions (e.g., Bart et al., 2005). Moffett et al. (2020) make the case that sensory experience and communication costs also matter. Future research could benefit from these 
Table 3 Research agenda

Research gap/topic area

Specific research questions

Theme 1: Enriching the conceptual foundations of buyer-seller interactions

A typology of modern buyer-seller interactions

Revisiting the concept of buyer-seller information (a)symmetry

1. How do buyer-seller interactions differ along the key dimensions of buyer-seller interactions (who, why, what, when, how)?

2. How do non-negotiation interactions differ from negotiations?

3. What are the key dimensions of buyer-seller information (a)symmetry?

4. How should these dimensions be precisely conceptualized and reliably measured (social desirability, specific aspects of offerings [e.g., pricing, quality], temporal differences over the customer journey, upstream versus downstream knowledge [Glazer, 1991], direction of the asymmetry, magnitude of the (a)symmetry, so on)?

5. What are the differential impacts of these dimensions of buyer-seller information (a)symmetry on buyers and sellers?

6. Along which dimensions are buyers gaining more information symmetry with sellers?

7. When do increases in information symmetry matter (e.g., the importance of the purchase, when offerings are standardized or customized, information intensity of the offerings, and when different value capture techniques [e.g., value-based pricing, conventional up-front pricing] are used)?

8. How do buyers who are at a disadvantage (e.g., customers in banking deserts, bottom of the pyramid customers) improve information symmetry to get better deals?

Theme 2: Examining change in buyers' perspectives: correlates of buyer's motivation-opportunity-ability to interact and buyers' decision mak-

ing

How do customers decide when to interact with sellers

How do customers decide how to interact with sellers

How have customers changed their judgment and decision making

Theme 3: Examining change in sellers' perspective: what value proposition to offer to buyers?

Transitioning into proactive information provision and management
9. What are the key determinants of customer decision on when to initiate an interaction with sellers?

10. What demotivates buyers' self-searching?

11. Are first impressions as important as traditional theories would predict when buyers and sellers interact with each other in so many ways?

12. How do customers choose which medium to interact with sellers?

13. How do buyers' and sellers' selective attention and encoding influence their behavior in the presence of the informational and technological shifts?

14. What are some strategies buyers use to leverage their power and knowledge when they interact with sellers?

15. As customer certainty increases and customers are more likely to be the initiator of buyer-seller interactions, how does their judgment and decision making change? Can certainty lead to more regrets?

16. When multiple media are used in buyer-seller interactions, how do buyers and sellers process information and integrate information?

17. How does customers' judgment and decision making change depending on the interaction format?

18. Can buyers and sellers both benefit from increases in information symmetry? When will increases in information symmetry harm sellers? (See also suggested research questions \#3 through \#8 above)

19. How do sellers transition from the role of information provision to the new role of information management?

20 . What are the key advantages and disadvantages of proactive information management? Boundary conditions of these advantages and disadvantages?

21. What can be the dark side of proactive information management on behalf of buyers? 
Table 3 (continued)

Research gap/topic area

How to sell to informed buyers who have more power and preference certainty

How to interact with informed buyers who prefer multiformat communications
Specific research questions

Addressing customer knowledge and power

22. Transparency selling tactics: when should sellers disclose more information to buyers?

23. Shifts to areas that sellers have more information than buyers, such as after-market and services: When does this tactic work? What are the contingencies? For how long the goodwill in the front-end will last? Under what condition would the goodwill created by an outside salesperson spillover to inside salespeople who take charge of aftermarket sales? Might customers see transparency in focal product negotiations but lack of transparency in aftermarket discussions as a bait-and-switch tactic?

24. To what extent can sellers use fairness appeals to mitigate the potential loss of profits to informed buyers?

25. What other creative strategies can sellers use to avoid or take advantage of the new power dynamics between them and informed buyers? What contextual factors moderate the power of buyers?

Dealing with increasing customer certainty

26. With the interaction moving to later stages of the buying cycle, how can sellers adjust their interaction strategy from product demos to other tactics to still be able to connect with the customer and build trust?

27. How should product demonstrations change to still be valuable to customers and help relationship building during that interaction (e.g., talking about features that are not readily available online during demonstrations)?

28. What are some effective ways for sellers to reduce buyers' certainty in their aspired price?

29. Is technology going to be part of the marketing mix, not just a means of interactions as traditionally conceptualized?

30. How to swiftly build trust: Which information communicated to customers is more likely to earn their trust?

31. How to achieve positive resonance when much of buyer-seller interaction is moving online?

32. How can sellers frame the interaction in a way that acknowledges both buyers' information and reduces their toughness? Can classic psychological theories (e.g., elaboration likelihood model, cognitive response theory) help in explaining/framing counterarguments?

33. What are some antecedents and consequences of effective multiformat communication?

34. How different videoconferencing interactions are from face-to-face ones? Can Zoom/Skype interactions be modified to get close to a faceto-face interaction?

35. How can firms foster positive shared experiences in digital formats? 
Table 3 (continued)

Research gap/topic area

New salesperson behavior
Specific research questions

36. What are the consequences of salesperson (in)accuracy in evaluating buyer-seller knowledge (a)symmetry?

37. How can salespeople re-open customers' minds to consider alternatives other than what the customer has already researched for?

38. Can salespeople be retrained to unlearn traditional selling tactics?

39. When and why are salespeople likely to reject technologies that actually enhance their effectiveness in information processing?

40. Can salespeople be effective when selling to both segments, less informed and more informed buyers?

41. How can salespeople alter their selling behavior, depending on the dynamics of information intensity of offerings?

42. How do salespeople respond to compensation plans that have creditsharing components, now that selling is performed by a broader set of selling actors?

Some research questions may fit into more than one topic

theories and frameworks to examine the impact of media choices and interaction outcomes.

\section{Revisiting the concept of buyer-seller information (a) symmetry}

It is naïve to assume that information symmetry is antithetical to information asymmetry and homogeneous across customers, stages of customer journey, and various offering attributes (e.g., products, services, pricing, quality). Furthermore, research on perceptual accuracy (Mullins et al., 2014) suggests that when examining buyer-seller differences such as information (a)symmetry, it is important to delineate between the magnitude of the difference (or a lack thereof) and the direction of the difference (e.g., do buyers have more information than sellers, or vice versa). In addition, because information intensity associated with an offering can change over time for specific categories (Glazer, 1991), buyer-seller information (a)symmetry can be dynamic. In Table 3, we provide a number of specific research questions related to this construct. A richer and more precise conceptualization of buyer-seller information (a)symmetry sets the stage for researchers to rigorously examine several important questions that we subsequently discuss.

\section{Examining change from the buyers' perspective}

Our review of negotiation research reveals that buyers have undergone fundamental changes in three ways. First, as a result of being more informed and prepared, customers now have higher certainty in their judgment and decision making (Ahearne et al., 2019b). This change is important, because much consumer research is based on judgment and decision making under uncertainty. Second, they are likely to engage with the seller much later in their decision-making process. This change challenges traditional buyer-seller interaction frameworks that assume relatively passive buyers and selling techniques that emphasize building awareness at the beginning of the interaction instead of jumping directly into persuasion. Third, they rely on more than one mode of communication when they interact with the seller (Moffett et al., 2020). Therefore, three key themes that warrant further research include how customers decide when and how to interact with sellers and how their judgment and decision-making has changed. Table 3 , Theme 2 provides some specific research questions.

To guide further research in this area, we believe the following insights from prior research on the choice of negotiation media are useful. First, Ambrose et al. (2008) find that face-to-face negotiations are preferred earlier in the relationship when uncertainties abound. As the relationship develops into a more certain phase, less rich media are used. Second, product buyers usually prefer the face-to-face medium for negotiation. Conversely, in service purchasing, perhaps because of the more ambiguous nature of services, buyers strive to exert more control over the relationship by using formal means such as email (Ambrose et al., 2008). Third, personality traits play a role in choosing a channel for negotiation (Geiger \& Laubert, 2018). For example, shy people prefer sending emails to talking on the telephone (Hertel et al., 2008). Fourth, the parties may use different media at different stages of negotiation (Geiger \& Laubert, 2018). Finally, people also vary in the way they interact and negotiate virtually, depending on personal, cultural, and gender differences (Rosette et al., 2012; Stuhlmacher et al., 2007). 


\section{Examining change from the sellers' perspective}

Many classic sales models assume information asymmetry and face-to-face interactions. However, insights from buyer-seller negotiation research seems to point to reduced effectiveness in traditional sellers' strategies when there are informational and technological shifts. While this perspective is important for practitioners to be aware of, we argue that a far-reaching, much more important implication of this change is to examine what value proposition sellers can offer customers, given these shifts. Our research agenda unpacks this question into four subthemes that are related to value proposition creation, communication, and delivery, including (1) transitioning into information provision and management, (2) how to sell to informed buyers who have more power and preference certainty, (3) how to interact with informed buyers who prefer multiformat communication, and (4) new salesperson behaviors.

\section{Transitioning into information provision and management}

A natural reaction to the decline of information asymmetry is for the seller to protect its information. However, recent research in buyer-seller negotiation shows that buyers and sellers can both benefit from increasing information symmetry (e.g., Atefi et al., 2020; Mohan et al., 2020). Nevertheless, one useful area for future research to explore is the contingencies of when increases in information symmetry can harm sellers. Furthermore, increases in information symmetry may represent an opportunity for sellers to shift from the traditional role of information provision to the new role of information management to create value for buyers. Specifically, buyers may view the seller's proactive information management more positively because of three reasons (e.g., Sternberg, 1985). First, buyers are flooded with information and find it hard to process the high volume of data available to them (e.g., analysis paralysis). This challenge depends on the information intensity of offerings (i.e., the levels of various types of information associated with offerings, see Glazer, 1991 for details). Second, sellers might be better equipped than buyers to combine information in inventive ways that creates solutions to customer problems. Third, buyers might not be skilled in combing new information with information they already have in memory. Therefore, buyers will be more likely to gravitate toward sellers whose value proposition includes helping customers manage these three aspects. Thus, a useful avenue for future research is to examine the advantages and disadvantages for seller firms and their salespeople when they shift from the traditional role of information provision to the new role of information management for buyers. To that end, it is important to adopt a systemic perspective to selling wherein not only salespeople but also multiple actors whose primary roles are not sales-centric (e.g., information technology staff) perform selling tasks (Hartmann et al., 2018).

\section{Selling to informed buyers who have more power and preference certainty}

Our review of negotiation research demonstrates how informational and technological shifts call for new ways of selling to buyers who have more power and preference certainty. We provide several specific research questions related to this subtheme in Table 3. In this regard, insights from negotiation research can help formulate some of these future research directions.

First, transparency-based selling tactics might be more effective. This is because the seller's transparency signals cooperativeness rather than competitiveness, thereby enhancing sellers' credibility and benevolence (Doney \& Cannon, 1997; Lusch et al., 2006). Transparency is an import issue, closely related to the reduced information asymmetry and its concomitant changes in buyer's bargaining power and aspirations, seller's aspirations, and the relational processes. Although negotiation research confirms transparency as an important strategy for earning customers' trust, increasing purchase likelihood, and forging long-term relationships (Atefi et al., 2020; Mohan et al., 2020), it remains unclear whether transparency-based selling tactics are still effective in various selling contexts, information intensity of offerings, and buyer-seller interaction formats.

Second, sellers can shift the bulk of their profits to areas in which they can still retain their information advantage. In many industries, these represent the aftermarkets or products or services that augment the main purchase (Reinartz \& Ulaga, 2008). For many software vendors, for example, customers are focused primarily on negotiating up-front license fees, while the bulk of vendor revenues come from back-end maintenance and update fees (Scavo, 2005). Similarly, more than $70 \%$ of an average auto dealership's profits come from the service, parts, and finance and insurance areas rather than from the front-end sales of new and used cars (Reed, 2013). In these aftermarkets, which have become the main profit engine of many industries (Suarez et al., 2013), companies still retain their information advantage because the primary focus of customers, as well as online resources and comparison websites, remains on front-end negotiations (Atefi et al., 2020). With the increasing importance of aftermarkets in driving profits in many industries, additional research on buyer-seller interactions in these aftermarkets is needed more than ever. However, with more industries adopting back-end products and services as the primary driver of their overall profits and with the asymmetry remaining in these aftermarkets, customers might perceive the transparency and trust-building in the frontend as a bait-and-switch strategy. Future research is needed 
to examine the contingencies under which this shift benefits sellers but also advances buyers' interests. Another possible avenue for future research is to examine the extent to which goodwill in the front-end will last after multiple rounds of aftermarket interactions (e.g., multiple service/maintenance interactions, etc.).

Third, sellers can rely on fairness-based sales tactics. In negotiations with unbalanced power between two parties, the stronger party tries to exploit its strength in favor of its own interests, while the weaker party strives to steer the negotiations toward a "fair" deal (Landau \& Pfetsch, 2000). With the tables turning with respect to power dynamics in buyer-seller negotiations, sellers might find that traditional aggressive strategies, such as giving a high opening offer to anchor buyers' counteroffers (Galinsky \& Mussweiler, 2001), came from a position of power and are no longer applicable in negotiating with buyers, who are now the stronger party. Buyers can now easily dictate their desired pricing, which is typically close to the publicly available information on the seller's cost or the true market value of the product, while sellers can hardly challenge them. Instead of challenging customers, however, sellers can appeal to their fairness by framing deals that, despite being different from what buyers were aspiring to get, are fair for both sides. Many scholars have demonstrated that, in addition to the outcome of the bargaining, negotiators are concerned about their social image and want to be perceived as fair (Andreoni \& Bernheim, 2009; Bolton \& Ockenfels, 2000). Future research can examine how sellers can effectively implement these tactics in various contexts.

Finally, researchers could explore how sellers can cope with the increased certainty of customers. The interaction with customers is now limited, as customers, who are more certain about what they want to appear in front of the seller's representatives only to close the deal. A correlate of this change is the reduced role of product demonstrations in buyer-seller initial interactions. Future research could identify strategies that firms can use to reduce customer certainty or cope with the more limited customer touchpoints throughout the buying journey.

\section{How to effectively communicate with buyers}

Our review reveals that sellers need new insights into how to effectively communicate with the new generation of buyers because of three reasons. First, for these buyers, face-to-face is not necessarily the preferred format of interaction. Second, it is likely to be difficult for sellers to build trust with informed buyers, particularly those with whom they interact briefly and over less rich media. Third, a number of existing theories [e.g., McGuire's (1969) hierarchy of effects model] does not fully reflect how modern buyer-seller interactions unfold when buyers play a much more active role.
Studies conducted in the early years of the Internet often focused on the ineffectiveness of new forms of buyer-seller negotiations, with an emphasis on how these new forms are inferior to traditional face-to-face interactions (McGinn \& Wilson, 2004; Valley, 2000). However, given the pervasiveness of this new form of bargaining, research has begun documenting the benefits of technology-facilitated interactions, such as the accessibility, transparency, and flatness of email bargaining (Byron, 2008). Indeed, research in this area has shifted from comparing email and face-to-face negotiations to examining negotiation strategies that are particularly effective in electronic bargaining (Singh et al., 2020). As mentioned earlier, recent theorization has also made a strong case for how technologies can improve the effectiveness, efficiency, and experience of buyer-seller interactions (Moffett et al., 2020).

In this regard, marketing research can benefit from insights in negotiation research on media choice and research in adjacent fields (e.g., psychology, communication, sociology) about the link between communication and persuasion. For example, Singh et al. (2020) ingeniously integrate influence theories with text-mining methodologies to study how textual cues can have an impact on customer attention and the likelihood of reaching a deal. Classic psychological theories such as inoculation theory (McGuire, 1961) can be useful in unpacking whether and how counterarguments and messages could be framed to reduce customers' certainty. Furthermore, research in psychology (Pennebaker, 1997) underscores how writing styles can evoke positive feelings, an area that holds important implications for textbased buyer-seller interactions and salesperson training. In addition, although buyer-seller interdependence may have changed fundamentally due to the informational and technological shifts, key principles to foster effectiveness in buyer-seller relationships may still hold [e.g., Kelley and Thibaut's (1978) interdependence theory]. Future research could build on and update these theories to examine modern buyer-seller interactions.

With the changes in the buying journey and the buyer-seller interactions becoming void of personal connections, developing happy and close relationships is likely more challenging than before. Research on "positivity resonance" explains how shared positive experiences could foster relationship-building (e.g., Fredrickson, 2001; Hall, 2020). With novel technologies that allow shared experiences in an online setting (e.g., Hasbro's online games, Gather.Town, etc.), firms can attenuate the negative impact of technological shifts and build relationships with customers in a digital environment. Future research can explore this avenue further.

While there is much research on email or text interactions, research on videoconferencing and how it differs from face-to-face interaction is scarce. As we mentioned earlier, 
videoconferencing tools such as Zoom get closer to face-toface experience by revealing facial micro-expressions but limit bodily cues and make eye contact impossible. However, they also allow seeing and correcting one's own facial expression, which is not possible in face-to-face and would offer interesting research directions. Newer technologies such as www.gather.town allow videoconferencing within physical contexts such as classrooms or conference hotels, which gets a lot closer to a face-to-face conversation. ${ }^{3}$ These advances can mitigate potential pitfalls of videoconferencing, including Zoom fatigue or feeling of loneliness (for instance, see Turkle, 2011). Future research can dive into these new formats and their relative benefits.

\section{Salesperson behavior}

The role of salespeople has fundamentally changed in the presence of the informational and technological shifts $(\mathrm{Oh}$, 2017). Furthermore, in line with the ecosystems perspective of selling, salespeople's ability to change the thinking and actions of buyers is increasingly more limited (Hartmann et al., 2018). However, salespeople remain an important aspect of buyer-seller interactions, even in the presence of informational and technological shifts that challenge their role in face-to-face interactions with buyers. This is particularly true in the $\mathrm{B} 2 \mathrm{~B}$ marketing context when long-term relationships are important. It is also true in the $\mathrm{B} 2 \mathrm{C}$ context when salespeople have to form a judgment and make decisions in a shorter time span, lest the customers will buy elsewhere. Our research agenda identifies several research questions regarding salesperson accuracy in their interactions with buyers and the issue of learning new sales tactics and unlearning old sales tactics to effectively sell to informed buyers.

\section{Conclusion}

Our inquiry focuses on informational and technological shifts that challenge the assumptions of many existing theories and frameworks in marketing. Reviewing findings in empirical research on negotiation in general and buyer-seller negotiations in particular, we illustrate how these assumption violations have been examined. Based on these insights, we develop a research agenda to guide future research on buyer-seller interactions in the modern world, where the informational and technological shifts continue to unravel. Although we organize the research questions in our agenda into three separate themes, there are complex interrelationships among them. For example, changes in buyers'

\footnotetext{
$\overline{3}$ We thank an anonymous reviewer for this interesting example.
}

and sellers' roles, power, and aspirations can bias the way both process information (e.g., motivated reasoning; Kunda, 1990) and subsequently influence other processes. Furthermore, because these effects likely vary across interaction episodes, longitudinal analyses would be useful to unpack the dynamics of buyer-seller interactions. Finally, to study these phenomena, scholars can leverage methodological advances to glean nuanced insights from under-researched aspects of buyer-seller interactions such as verbal and textual cues (e.g., Marinova et al., 2018; Singh et al., 2018, 2020) and to demonstrate causal effects instead of correlations (e.g., Ahearne et al., 2019a).

Acknowledgements The authors thank three anonymous reviewers for their constructive comments and suggestions on earlier versions of the manuscript.

Author's contribution MA: All authors contributed equally and are listed alphabetically.

\section{References}

Accenture. (2014). 2014 State of B2B procurement study: Uncovering the shifting landscape in $B 2 B$ commerce. Accenture interactivePoint of view series. Accenture.

Adair, W. L., \& Brett, J. M. (2005). The negotiation dance: Time, culture, and behavioral sequences in negotiation. Organization Science, 16(1), 33-51.

Ahearne, M., Atefi, Y., Hall, Z., Hohenberg, S., \& Zettelmeyer, F. (2019a). Information disclosure in negotiating with informed customers. Marketing Science Institute Report No. 19-129.

Ahearne, M., Hall, Z., Krishnamurthy, P., \& Pourmasoudi, M. (2019b). Selling in the digital age. Marketing Science Institute Report No. 19-123.

Alavi, S., Habel, J., Guenzi, P., \& Wieseke, J. (2018). The role of leadership in salespeople's price negotiation behavior. Journal of the Academy of Marketing Science, 46(4), 703-724.

Ambrose, E., Marshall, D., Fynes, B., \& Lynch, D. (2008). Communication media selection in buyer-supplier relationships. International Journal of Operations \& Production Management, 28(4), $360-379$.

An, M. (2016). Buyers speak out: How sales needs to evolve. Retrieved April 16, 2021, from https://blog.hubspot.com/sales/ buyers-speak-out-how-sales-needs-to-evolve

Andreoni, J., \& Bernheim, B. D. (2009). Social image and the 50-50 norm: A theoretical and experimental analysis of audience effects. Econometrica, 77(5), 1607-1636.

Atefi, Y., Ahearne, M., Hohenberg, S., Hall, Z., \& Zettelmeyer, F. (2020). Open negotiation: The back-end benefits of salespeople's transparency in the front end. Journal of Marketing Research, 57(6), 1076-1094.

Backus, M., Blake, T., Larsen, B., \& Tadelis, S. (2020). Sequential bargaining in the field: Evidence from millions of online bargaining interactions. Quarterly Journal of Economics, 135(3), 1319-1361.

Bagchi, R., \& Cheema, A. (2013). The effect of red background color on willingness-to-pay: The moderating role of selling mechanism. Journal of Consumer Research, 39(5), 947-960.

Baltes, B. B., Dickson, M. W., Sherman, M. P., Bauer, C. C., \& LaGanke, J. S. (2002). Computer-mediated communication and 
group decision making: A meta-analysis. Organizational Behavior and Human Decision Processes, 87(1), 156-179.

Barsness, Z. I., \& Bhappu, A. D. (2004). At the crossroads of culture and technology social influence and information-sharing processes during negotiation. In M. J. Gelfand \& J. M. Breet (Eds.), The handbook of negotiation and culture (pp. 350-373). Stanford Business Books.

Bart, Y., Shankar, V., Sultan, F., \& Urban, G. L. (2005). Are the drivers and role of online trust the same for all web sites and consumers? A large-scale exploratory empirical study. Journal of Marketing, 69(4), 133-152.

Bazerman, M. H., \& Neale, M. A. (1993). Negotiating rationally. Free Press.

Blanchard, S. J., Hada, M., \& Carlson, K. A. (2018). Specialist competitor referrals: How salespeople can use competitor referrals for nonfocal products to increase focal product sales. Journal of Marketing, 82(4), 127-145.

Bleier, A., Harmeling, C. M., \& Palmatier, R. W. (2019). Creating effective online customer experiences. Journal of Marketing, 83(2), 98-119.

Boichuk, J. P., Bolander, W., Hall, Z. R., Ahearne, M., Zahn, W. J., \& Nieves, M. (2014). Learned helplessness among newly hired salespeople and the influence of leadership. Journal of Marketing, 78(1), 95-111.

Bolton, G. E., \& Ockenfels, A. (2000). ERC: A theory of equity, reciprocity, and competition. American Economic Review, 90(1), 166-193.

Brett, J., \& Thompson, L. (2016). Negotiation. Organizational Behavior and Human Decision Processes, 136(September), 68-79.

Brown, H. D., \& Lee, H. (1994). Teaching by principles: An interactive approach to language pedagogy. Prentice Hall Regents.

Byron, K. (2008). Carrying too heavy a load? The communication and miscommunication of emotion by email. Academy of Management Review, 33(2), 309-327.

Chatterjee, K., \& Samuelson, W. (1983). Bargaining under incomplete information. Operations Research, 31(5), 835-851.

Citera, M., Beauregard, R., \& Mitsuya, T. (2005). An experimental study of credibility in e-negotiations. Psychology \& Marketing, 22(2), 163-179.

Cox Automotive. (2019). 2019 Car buyer journey study. https://www. coxautoinc.com/market-insights/2019-car-buyer-journey-study/

Croson, R. T. A. (1999). Look at me when you say that: An electronic negotiation simulation. Simulation \& Gaming, 30(1), 23-37.

Daft, R. L., \& Lengel, R. H. (1983). Information richness. A new approach to managerial behavior and organization design. Texas A\&M University.

Daft, R. L., \& Lengel, R. H. (1986). Organizational information requirements, media richness and structural design. Management Science, 32(5), 554-571.

Dennis, A., Fuller, R., \& Valacich, J. (2009). Media synchronicity and media choice. In T. Hartmann (Ed.), Media choice: A theoretical and empirical overview (pp. 247-273). Routledge.

Dennis, A. R., Fuller, R. M., \& Valacich, J. S. (2008). Media, tasks, and communication processes: A theory of media synchronicity. MIS Quarterly, 32(3), 575-600.

Dixon, M., \& Adamson, B. (2011). The challenger sale: Taking control of the customer conversation. Penguin.

DMEautomotive. (2014). New research: 1 in 6 car buyers skips testdrive; Nearly half visit just one (or no) dealership prior to purchase. PR Newswire. https://www.prnewswire.com/news-relea ses/new-research-1-in-6-car-buyers-skips-test-drive-nearly-halfvisit-just-one-or-no-dealership-prior-to-purchase-255302891. html

Doney, P. M., \& Cannon, J. P. (1997). An examination of the nature of trust in buyer-seller relationships. Journal of Marketing, 61(2), $35-51$.
Drolet, A. L., \& Morris, M. W. (2000). Rapport in conflict resolution: Accounting for how face-to-face contact fosters mutual cooperation in mixed-motive conflicts. Journal of Experimental Social Psychology, 36(1), 26-50.

Ebner, N. (2007). Trust-building in e-negotiation. In L. Brennan \& V. Johnson (Eds.), Computer-mediated relationships and trust managerial and organizational effects (pp. 139-157). Information Science Publishing.

Eckhardt, G. M., Houston, M. B., Jiang, B., Lamberton, C., Rindfleisch, A., \& Zervas, G. (2019). Marketing in the sharing economy. Journal of Marketing, 83(5), 5-27.

El-Shinnawy, M. M., \& Markus, M. L. (1992). Media richness theory and new electronic communication media: A study of voice mail and electronic mail. In International conference on information systems 1992 proceedings (pp. 91-105).

Frazier, G. L. (1983). Interorganizational exchange behavior in marketing channels: A broadened perspective. Journal of Marketing, 47(4), 68-78.

Fredrickson, B. L. (2001). The role of positive emotions in positive psychology: The broaden-and-build theory of positive emotions. American Psychologist, 56(3), 218-226.

Friedman, R. A., \& Currall, S. C. (2003). Conflict escalation: Dispute exacerbating elements of e-mail communication. Human Relations, 56(11), 1325-1347.

Galin, A., Gross, M., \& Gosalker, G. (2007). E-negotiation versus face-to-face negotiation what has changed-If anything? Computers in Human Behavior, 23(1), 787-797.

Galinsky, A. D., \& Mussweiler, T. (2001). First offers as anchors: The role of perspective-taking and negotiator focus. Journal of Personality and Social Psychology, 81(4), 657-669.

Galinsky, A. D., Mussweiler, T., \& Medvec, V. H. (2002). Disconnecting outcomes and evaluations: The role of negotiator focus. Journal of Personality and Social Psychology, 83(5), 1131-1140.

Geiger, I. (2014). Media effects on the formation of negotiator satisfaction: The example of face-to-face and text based electronically mediated negotiations. Group Decision and Negotiation, 23(4), $735-763$.

Geiger, I., \& Laubert, C. (2018). Situational strategic versus personal influences on negotiation medium choice. International Journal of Conflict Management, 29(3), 398-423.

Geiger, I., \& Parlamis, J. (2014). Is there more to email negotiation than email? The role of email affinity. Computers in Human Behavior, 32, 67-78.

Glazer, R. (1991). Marketing in an information-intensive environment: Strategic implications of knowledge as an asset. Journal of Marketing, 55(4), 1-19.

Gorzelany, J. (2014). Car buyers flunking their test drives, stats show-Here's how to do it right. Forbes. https://www. forbes.com/sites/jimgorzelany/2014/04/25/car-buyers-flunk ing-their-test-drives-stats-show-heres-how-to-do-it-right/

Grewal, D., Hulland, J., Kopalle, P. K., \& Karahanna, E. (2020). The future of technology and marketing: A multidisciplinary perspective. Journal of the Academy of Marketing Science, 48, 1-8.

Hall, J. A. (2020). Relating through technology. Cambridge University Press.

Hartmann, N. N., Wieland, H., \& Vargo, S. L. (2018). Converging on a new theoretical foundation for selling. Journal of Marketing, $82(2), 1-18$.

Heiman, A., \& Muller, E. (1996). Using demonstration to increase new product acceptance: Controlling demonstration time. Journal of Marketing Research, 33(4), 422-430.

Hertel, G., Schroer, J., Batinic, B., \& Naumann, S. (2008). Do shy people prefer to send e-mail? Personality effects on communication media preferences in threatening and nonthreatening situations. Social Psychology, 39(4), 231-243. 
Hine, M. J., Murphy, S. A., Weber, M., \& Kersten, G. (2009). The role of emotion and language in dyadic e-negotiations. Group Decision and Negotiation, 18(3), 193-211.

Hochstein, B., Bolander, W., Goldsmith, R., \& Plouffe, C. R. (2019). Adapting influence approaches to informed consumers in highinvolvement purchases: Are salespeople really doomed? Journal of the Academy of Marketing Science, 47(1), 118-137.

Homburg, C., Wieseke, J., \& Bornemann, T. (2009). Implementing the marketing concept at the employee-customer interface: The role of customer need knowledge. Journal of Marketing, 73(4), 64-81.

Huang, X., Gattiker, T. F., \& Schwarz, J. L. (2008). Interpersonal trust formation during the supplier selection process: The role of the communication channel. Journal of Supply Chain Management, 44(3), 53-75.

Hüffmeier, J., Freund, P. A., Zerres, A., Backhaus, K., \& Hertel, G. (2014). Being tough or being nice? A meta-analysis on the impact of hard- and softline strategies in distributive negotiations. Journal of Management, 40(3), 866-892.

Jain, B. A., \& Solomon, J. S. (2000). The effect of task complexity and conflict handling styles on computer-supported negotiations. Information \& Management, 37(4), 161-168.

Johnson, N. A., \& Cooper, R. B. (2009a). Media, affect, concession, and agreement in negotiation: IM versus telephone. Decision Support Systems, 46(3), 673-684.

Johnson, N. A., \& Cooper, R. B. (2009b). Power and concession in computer-mediated negotiations: An examination of first offers. MIS Quarterly, 33(1), 147-170.

Kahneman, D., \& Tversky, A. (1979). Prospect theory: An analysis of decision under risk. Econometrica, 47(2), 263-291.

Kelley, H. H., \& Thibaut, J. W. (1978). Interpersonal relations: A theory of interdependence. Wiley.

Khan, M. A., \& Ebner, N. (Eds.). (2019). The Palgrave handbook of cross-cultural business negotiation. Palgrave Macmillan.

Köhler, C. F., Rohm, A. J., de Ruyter, K., \& Wetzels, M. (2011). Return on interactivity: The impact of online agents on newcomer adjustment. Journal of Marketing, 75(2), 93-108.

Kruger, J., Epley, N., Parker, J., \& Ng, Z.-W. (2005). Egocentrism over e-mail: Can we communicate as well as we think? Journal of Personality and Social Psychology, 89(6), 925-936.

Kuksov, D., \& Liao, C. (2018). When showrooming increases retailer profit. Journal of Marketing Research, 55(4), 459-473.

Kumar, V., \& Venkatesan, R. (2005). Who are the multichannel shoppers and how do they perform? Correlates of multichannel shopping behavior. Journal of Interactive Marketing, 19(2), 44-62.

Kunda, Z. (1990). The case for motivated reasoning. Psychological Bulletin, 108(3), 480-498.

Lam, S. K., Sleep, S., Hennig-Thurau, T., Sridhar, S., \& Saboo, A. R. (2017). Leveraging frontline employees' small data and firmlevel big data in frontline management: An absorptive capacity perspective. Journal of Service Research, 20(1), 12-28.

Landau, P. R., \& Pfetsch, A. (2000). Symmetry and asymmetry in international negotiations. International Negotiation, 5(1), 21-42.

Laubert, C., \& Parlamis, J. (2019). Are you angry (happy, sad) or aren't you? Emotion detection difficulty in email negotiation. Group Decision and Negotiation, 28(1), 377-413.

Lee, H., Deng, X., Unnava, H. R., \& Fujita, K. (2014). Monochrome forests and colorful trees: The effect of black-and-white versus color imagery on construal level. Journal of Consumer Research, 41(4), 1015-1032.

Leigh, T. W., \& McGraw, P. F. (1989). Mapping the procedural knowledge of industrial sales personnel: A script-theoretic investigation. Journal of Marketing, 53(1), 16-34.

Lemon, K. N., \& Verhoef, P. C. (2016). Understanding customer experience throughout the customer journey. Journal of Marketing, 80(6), 69-96.
Lindsay, P. H., \& Norman, D. A. (2013). Human information processing: an introduction to psychology. Academic press.

Lusch, R. F., Vargo, S. L., \& Malter, A. J. (2006). Marketing as service-exchange: Taking a leadership role in global marketing management. Organizational Dynamics, 35(3), 264-278.

MacInnis, D. J. (2011). A framework for conceptual contributions in marketing. Journal of Marketing, 75(4), 136-154.

Marinova, D., Singh, S. K., \& Singh, J. (2018). Frontline problemsolving effectiveness: A dynamic analysis of verbal and nonverbal cues. Journal of Marketing Research, 55(2), 178-192.

Martin, K. D., Borah, A., \& Palmatier, R. W. (2017). Data privacy: Effects on customer and firm performance. Journal of Marketing, 81(1), 36-58.

McGinn, K. L., \& Wilson, E. (2004). How to negotiate successfully online. Negotiation, 2(3), 3-5.

McGuire, W. J. (1961). Resistance to persuasion conferred by active and passive prior refutation of same and alternative counterarguments. Journal of Abnormal Psychology, 63(2), 326-332.

McGuire, W. J. (1969). The nature of attitudes and attitude change. In G. Lindsey \& E. Aronson (Eds.), The handbook of social psychology (Vol. 3, pp. 136-314). Addison-Wesley.

Mehrabian, A. (2017). Nonverbal communication. Routledge.

Mikalef, P., Krogstie, J., Pappas, I. O., \& Pavlou, P. (2020). Exploring the relationship between big data analytics capability and competitive performance: The mediating roles of dynamic and operational capabilities. Information \& Management, 57(2), 103169.

Mishra, D. P., Heide, J. B., \& Cort, S. G. (1998). Information asymmetry and levels of agency relationships. Journal of Marketing Research, 19(4), 277-295.

Moffett, J. W., Folse, J. A. G., \& Palmatier, R. W. (2020). A theory of multiformat communication: mechanisms, dynamics, and strategies. Journal of the Academy of Marketing Science, 49(3), 441-461.

Mohan, B., Buell, R. W., \& John, L. K. (2020). Lifting the veil: The benefits of cost transparency. Marketing Science, 39(6), $1105-1121$.

Moorman, C., Diehl, K., Brinberg, D., \& Kidwell, B. (2004). Subjective knowledge, search locations, and consumer choice. Journal of Consumer Research, 31(3), 673-680.

Morgan, R. M., \& Hunt, S. D. (1994). The commitment-trust theory of relationship marketing. Journal of Marketing, 58(3), 20-38.

Morrissey, R., Stricker, K., Tsang, R., \& Zayer, E. (2017). The future of car sales is omnichannel. Bain \& Company. https://www.bain. com/insights/the-future-of-car-sales-is-omnichannel/

Morton, F. S., Silva-Risso, J., \& Zettelmeyer, F. (2011). What matters in a price negotiation: Evidence from the US auto retailing industry. Quantitative Marketing and Economics, 9(4), 365-402.

Mullins, R. R., Ahearne, M., Lam, S. K., Hall, Z. R., \& Boichuk, J. P. (2014). Know your customer: How salesperson perceptions of customer relationship quality form and influence account profitability. Journal of Marketing, 78(6), 38-58.

Naquin, C. E., \& Paulson, G. D. (2003). Online bargaining and interpersonal trust. Journal of Applied Psychology, 88(1), 113-120.

Neslin, S. A., Grewal, D., Leghorn, R., Shankar, V., Teerling, M. L., Thomas, J. S., \& Verhoef, P. C. (2006). Challenges and opportunities in multichannel customer management. Journal of Service Research, 9(2), 95-112.

Oh, J. H. (2017). A conceptual framework for successful salesperson role change management. Journal of Business \& Industrial Marketing, 32(8), 1136-1143.

Ophir, E., Nass, C., \& Wagner, A. D. (2009). Cognitive control in media multitaskers. Proceedings of the National Academy of Sciences, 106(37), 15583-15587.

Paese, P. W., Schreiber, A. M., \& Taylor, A. W. (2003). Caught telling the truth: Effects of honesty and communication media in 
distributive negotiations. Group Decision and Negotiation, 12(6), 537-566.

Palmatier, R. W., Houston, M. B., \& Hulland, J. (2018). Review articles: Purpose, process, and structure. Journal of the Academy of Marketing Science, 46(1), 1-5.

Parlamis, J. D., \& Geiger, I. (2015). Mind the medium: A qualitative analysis of email negotiation. Group Decision and Negotiation, 24(2), 359-381.

Pennebaker, J. W. (1997). Writing about emotional experiences as a therapeutic process. Psychological Science, 8(3), 162-166.

Perdue, B. C., \& Summers, J. O. (1991). Purchasing agents' use of negotiation strategies. Journal of Marketing Research, 28(2), 175-189.

Pesendorfer, E.-M., \& Koeszegi, S. T. (2006). Hot versus cool behavioural styles in electronic negotiations: The impact of communication mode. Group Decision and Negotiation, 15(2), 141-155.

Pinkley, R. L., Neale, M. A., \& Bennett, R. J. (1994). The impact of alternatives to settlement in dyadic negotiation. Organizational Behavior and Human Decision Processes, 57(1), 97-116.

Purdy, J. M., Nye, P., \& Balakrishnan, P. V. (2000). The impact of communication media on negotiation outcomes. International Journal of Conflict Management, 11(2), 162-187.

Rapp, A., Bachrach, D. G., Panagopoulos, N., \& Ogilvie, J. (2014). Salespeople as knowledge brokers: A review and critique of the challenger sales model. Journal of Personal Selling \& Sales Management, 34(4), 245-259.

Ratchford, B. T., Lee, M.-S., \& Talukdar, D. (2003). The impact of the Internet on information search for automobiles. Journal of Marketing Research, 40(2), 193-209.

Reed, P. (2013). Where does the car dealer make money? Retrieved May 10, 2015, from http://www.edmunds.com/car-buying/ where-does-the-car-dealer-make-money.html

Reinartz, W., \& Ulaga, W. (2008). How to sell services more profitably. Harvard Business Review, 86(5), 90-96, 129.

Rosette, A. S., Brett, J. M., Barsness, Z., \& Lytle, A. L. (2012). When cultures clash electronically: The impact of email and social norms on negotiation behavior and outcomes. Journal of CrossCultural Psychology, 43(4), 628-643.

Samuelson, W. (1984). Bargaining under asymmetric information. Econometrica, 52(4), 995-1005.

Scavo, F. (2005). High software maintenance fees and what to do about them. Retrieved July 8, 2016, from http://www.computereconomi cs.com/article.cfm?id=1033

Sheth, J. N. (1975). Buyer-seller interaction: A conceptual framework. In G. Zaltman \& B. Sternthal (Eds.), SV-Broadening the concept of consumer behavior (pp. 131-140). Association for Consumer Research.

Shi, M., Yang, B., \& Chiang, J. (2018). Dyad calling behavior: Asymmetric power and tie strength dynamics. Journal of Interactive Marketing, 42, 63-79.

Siebert, A., Gopaldas, A., Lindridge, A., \& Simões, C. (2020). Customer experience journeys: Loyalty loops versus involvement spirals. Journal of Marketing, 84(4), 45-66.

Siegel, S., \& Fouraker, L. E. (1960). Bargaining and group decision making: Experiments in bilateral monopoly. McGraw-Hill.

Singh, J., Flaherty, K., Sohi, R. S., Deeter-Schmelz, D., Habel, J., Le Meunier-FitzHugh, K. L., Malshe, A., Mullins, R., \& Onyemah, V. (2019). Sales profession and professionals in the age of digitization and artificial intelligence technologies: Concepts, priorities, and questions. Journal of Personal Selling \& Sales Management, 39(1), 2-22.

Singh, S., Marinova, D., Singh, J., \& Evans, K. R. (2018). Customer query handling in sales interactions. Journal of the Academy of Marketing Science, 46(5), 837-856.
Singh, S. K., Marinova, D., \& Singh, J. (2020). Business-to-business e-negotiations and influence tactics. Journal of Marketing, 84(2), 47-68.

Small, D. A., \& Loewenstein, G. (2003). Helping a victim or helping the victim: Altruism and identifiability. Journal of Risk and Uncertainty, 26(1), 5-16.

Solomon, M. R., Surprenant, C., Czepiel, J. A., \& Gutman, E. G. (1985). A role theory perspective on dyadic interactions: The service encounter. Journal of Marketing, 49(1), 99-111.

Srivastava, J., \& Chakravarti, D. (2009). Channel negotiations with information asymmetries: Contingent influences of communication and trustworthiness reputations. Journal of Marketing Research, 46(4), 557-572.

Steinhoff, L., Arli, D., Weaven, S., \& Kozlenkova, I. V. (2019). Online relationship marketing. Journal of the Academy of Marketing Science, 47(3), 369-393.

Sternberg, R. J. (1985). Implicit theories of intelligence, creativity, and wisdom. Journal of Personality and Social Psychology, 49(3), 607-627.

Stuhlmacher, A. F., \& Citera, M. (2005). Hostile behavior and profit in virtual negotiation: A meta-analysis. Journal of Business and Psychology, 20(1), 69-93.

Stuhlmacher, A. F., Citera, M., \& Willis, T. (2007). Gender differences in virtual negotiation: Theory and research. Sex Roles: A Journal of Research, 57(5-6), 329-339.

Suarez, F. F., Cusumano, M. A., \& Kahl, S. J. (2013). Services and the business models of product firms: An empirical analysis of the software industry. Management Science, 59(2), 420-435.

Thomas, J. S., \& Sullivan, U. Y. (2005). Managing marketing communications with multichannel customers. Journal of Marketing, 69(4), 239-251.

Thomaz, F., Salge, C., Karahanna, E., \& Hulland, J. (2020). Learning from the dark web: Leveraging conversational agents in the era of hyper-privacy to enhance marketing. Journal of the Academy of Marketing Science, 48(1), 43-63.

Thompson, L. (1995). The impact of minimum goals and aspirations on judgments of success in negotiations. Group Decision and Negotiation, 4(6), 513-524.

Thompson, L. (2006). Negotiation theory and research. Psychology Press.

Thompson, L., \& Nadler, J. (2002). Negotiating via information technology: Theory and application. Journal of Social Issues, 58(1), 109-124.

Thompson, S. A., Kim, M., \& Smith, K. M. (2016). Community participation and consumer-to-consumer helping: Does participation in third party-hosted communities reduce one's likelihood of helping? Journal of Marketing Research, 53(2), 280-295.

Turkle, S. (2011). Alone together: Why we expect more from technology and less from each other. Basic Books.

Valley, K. L. (2000). The electronic negotiator. Harvard Business Review, 78(1), 16-17.

Van Doorn, J., Lemon, K. N., Mittal, V., Nass, S., Pick, D., Pirner, P., \& Verhoef, P. C. (2010). Customer engagement behavior: Theoretical foundations and research directions. Journal of Service Research, 13(3), 253-266.

Van Doorn, J., Mende, M., Noble, S. M., Hulland, J., Ostrom, A. L., Grewal, D., \& Petersen, J. A. (2017). Domo arigato Mr. Roboto: Emergence of automated social presence in organizational frontlines and customers' service experiences. Journal of Service Research, 20(1), 43-58.

Verhoef, P. C., Lemon, K. N., Parasuraman, A., Roggeveen, A., Tsiros, M., \& Schlesinger, L. A. (2009). Customer experience creation: Determinants, dynamics and management strategies. Journal of Retailing, 85(1), 31-41. 
Wallace, D. W., Giese, J. L., \& Johnson, J. L. (2004). Customer retailer loyalty in the context of multiple channel strategies. Journal of Retailing, 80(4), 249-263.

Wang, H.-C., \& Doong, H.-S. (2014). Revisiting the task-media fit circumflex: A further examination of negotiation tasks. Information \& Management, 51(6), 738-746.

Weisband, S., \& Atwater, L. (1999). Evaluating self and others in electronic and face-to-face groups. Journal of Applied Psychology, 84(4), 632-639.

White, S. B., \& Neale, M. A. (1991). Reservation prices, resistance points, and BATNAs: Determining the parameters of acceptable negotiated outcomes. Negotiation Journal, 7(4), 379-388.

White, S. B., \& Neale, M. A. (1994). The role of negotiator aspirations and settlement expectancies in bargaining outcomes. Organizational Behavior and Human Decision Processes, 57(2), 303-317.

White, S. B., Valley, K. L., Bazerman, M. H., Neale, M. A., \& Peck, S. R. (1994). Alternative models of price behavior in dyadic negotiations: Market prices, reservation prices, and negotiator aspirations. Organizational Behavior and Human Decision Processes, 57(3), 430-447.
Yadav, M. S., \& Pavlou, P. A. (2014). Marketing in computer-mediated environments: Research synthesis and new directions. Journal of Marketing, 78(1), 20-40.

Yadav, M. S., \& Pavlou, P. A. (2020). Technology-enabled interactions in digital environments: A conceptual foundation for current and future research. Journal of the Academy of Marketing Science, 48(1), 132-136.

Yang, M. H., Lin, B., Chandlrees, N., \& Chao, H. Y. (2009). The effect of perceived ethical performance of shopping websites on consumer trust. Journal of computer information systems, 50(1), $15-24$.

Zettelmeyer, F., Morton, F. S., \& Silva-Risso, J. (2006). How the Internet lowers prices: Evidence from matched survey and automobile transaction data. Journal of Marketing Research, 43(2), 168-181.

Publisher's note Springer Nature remains neutral with regard to jurisdictional claims in published maps and institutional affiliations. 